\title{
Volatile organic compound measurements at Trinidad Head, California, during ITCT 2K2: Analysis of sources, atmospheric composition, and aerosol residence times
}

\author{
Dylan B. Millet, ${ }^{1}$ Allen H. Goldstein, ${ }^{1}$ James D. Allan, ${ }^{2}$ Timothy S. Bates, ${ }^{3}$ \\ Hacene Boudries, ${ }^{4}$ Keith N. Bower, ${ }^{2}$ Hugh Coe, ${ }^{2}$ Yilin Ma, ${ }^{5}$ Megan McKay, ${ }^{1}$ \\ Patricia K. Quinn, ${ }^{3}$ Amy Sullivan, ${ }^{5}$ Rodney J. Weber, ${ }^{5}$ and Douglas R. Worsnop ${ }^{4}$ \\ Received 30 July 2003; revised 23 October 2003; accepted 29 October 2003; published 7 July 2004.
}

[1] We report hourly in-situ observations of $\mathrm{C}_{1}-\mathrm{C}_{8}$ speciated volatile organic compounds (VOCs) obtained at Trinidad Head CA in April and May 2002 as part of the NOAA Intercontinental Transport and Chemical Transformation study. Factor analysis of the VOC data set was used to define the dominant processes driving atmospheric chemical composition at the site, and to characterize the sources for measured species. Strong decreases in background concentration were observed for several of the VOCs during the experiment due to seasonal changes in $\mathrm{OH}$ concentration. $\mathrm{CO}$ was the most important contributor to the total measured $\mathrm{OH}$ reactivity at the site at all times. Oxygenated VOCs were the primary component of both the total VOC burden and of the VOC OH reactivity, and their relative importance was enhanced under conditions when local source contributions were minimal. VOC variability exhibited a strong dependence on residence time $\left(\mathrm{s}_{\operatorname{lnX}}=1.55 \tau^{-0.44}, \mathrm{r}^{2}=0.98\right.$; where $\mathrm{s}_{\operatorname{lnX}}$ is the standard deviation of the natural logarithm of the mixing ratio), and this relationship was used, in conjunction with measurements of ${ }^{222} \mathrm{Rn}$, to estimate the average $\mathrm{OH}$ concentration during the study period $\left(6.1 \times 10^{5} \mathrm{molec} / \mathrm{cm}^{3}\right)$. We also employed the variability-lifetime relationship defined by the VOC data set to estimate submicron aerosol residence times as a function of chemical composition. Two independent measures of aerosol chemical composition yielded consistent residence time estimates. Lifetimes calculated in this manner were between 3-7 days for aerosol nitrate, organics, sulfate, and ammonium. The lifetime estimate for methane sulfonic acid ( $\sim 12$ days) was slightly outside of this range. The lifetime of the total aerosol number density was estimated at 9.8 days. INDEX TERMS: 0305 Atmospheric Composition and Structure: Aerosols and particles (0345, 4801); 0365 Atmospheric Composition and Structure: Troposphere-composition and chemistry; 0368 Atmospheric Composition and Structure: Troposphere-constituent transport and chemistry; KEYWORDS: atmospheric chemistry, volatile organic compounds, aerosol

Citation: Millet, D. B., et al. (2004), Volatile organic compound measurements at Trinidad Head, California, during ITCT 2K2: Analysis of sources, atmospheric composition, and aerosol residence times, J. Geophys. Res., 109, D23S16, doi:10.1029/2003JD004026.

\section{Introduction}

[2] Volatile organic compounds (VOCs) play a central role in the composition of the troposphere as precursors to ozone and secondary organic aerosol, by impacting the

\footnotetext{
${ }^{1}$ ESPM, Ecosystem Sciences, University of California, Berkeley, California, USA.

${ }^{2}$ Department of Physics, University of Manchester Institute of Science and Technology, Manchester, UK.

${ }^{3}$ Pacific Marine Environmental Laboratory, NOAA, Seattle, Washington, USA

${ }^{4}$ Aerodyne Research Incorporated, Billerica, Massachusetts, USA.

${ }^{5}$ School of Earth and Atmospheric Sciences, Georgia Institute of Technology, Atlanta, Georgia, USA.
}

Copyright 2004 by the American Geophysical Union. 0148-0227/04/2003JD004026\$09.00
Earth's radiative budget, and by enabling the export of $\mathrm{NO}_{\mathrm{x}}$ from source regions in the form of peroxyacetyl nitrate (PAN) and related compounds. VOCs are introduced into the atmosphere via a wide range of anthropogenic, biogenic and photochemical sources, and have a correspondingly wide array of functionalities, encompassing hydrocarbons as well as oxygenated, halogenated and aromatic species, along with other heterocompounds such as dimethylsulfide (DMS) and acetonitrile. Atmospheric residence times of VOCs with respect to photochemical loss span many orders of magnitude, from a few hours or less to hundreds of years. On-site VOC measurements, in addition to helping to quantify regional photochemistry, can thus provide useful insights regarding the nature and number of source types impacting the sampling region [e.g., Goldstein and Schade, 2000], physiological processes driving biogenic emissions 
[e.g., Fuentes et al., 2000], photochemical aging, and atmospheric transport [e.g., Parrish et al., 1992; McKeen and Liu, 1993].

[3] The Intercontinental Transport and Chemical Transformation 2002 (ITCT 2K2) study was carried out in the spring of 2002, with the primary goal of better quantifying the transport of pollution, in particular $\mathrm{CO}$, ozone and its precursors, fine particles, and other chemically and radiatively active compounds, into North America. As part of ITCT $2 \mathrm{~K} 2$, a ground site was established at Trinidad Head, on the northern California coast, and equipped with instrumentation for in-situ measurement of hourly speciated VOC concentrations and an array of aerosol parameters, as well as supporting meteorological and trace gas data. This paper presents the VOC data from Trinidad Head with the following objectives: quantifying inflow boundary conditions for the chemical composition of air entering North America from the Pacific Ocean marine boundary layer; examining the dominant source types impacting air mass composition at Trinidad Head and evaluating the importance of these sources for measured species; estimating the average hydroxyl radical abundance in air masses en route to Trinidad Head; and estimating atmospheric residence times for various chemical components of aerosols.

\section{Experiment}

\subsection{Field Site}

[4] In April 2002, a ground-based coastal field site was established at Trinidad Head, CA (41.054 N, 124.151 W, $107 \mathrm{~m}$ elevation) as part of the NOAA ITCT $2 \mathrm{~K} 2$ study. Instrumentation was housed in a climate controlled laboratory, and sampling inlets were mounted on a $10 \mathrm{~m}$ scaffolding tower beside the laboratory container. On-site measurements of a suite of gas- and particle-phase species and meteorological parameters were made during the experiment (19 April-22 May).

\subsection{Measurements}

[5] VOCs were measured hourly with a fully automated, in-situ, two-channel gas chromatograph with mass selective and flame ionization detectors (GC/MSD/FID). This system is described in detail elsewhere [Millet et al., 2004] and is discussed only briefly here. The FID channel was configured for analysis of $\mathrm{C}_{3}-\mathrm{C}_{6}$ alkanes, alkenes, and alkynes, and the MSD channel for analysis of a range of other VOCs, including aromatic, oxygenated and halogenated compounds. For 36 minutes out of every hour, two subsample flows $(15 \mathrm{scc} / \mathrm{m})$ were drawn from the main sample line $(4 \mathrm{sl} / \mathrm{m})$ and passed through a preconditioning trap for the removal of water (Teflon tube cooled thermoelectrically to $-25^{\circ} \mathrm{C}$ ). Carbon dioxide and ozone were scrubbed from the FID channel subsample (Ascarite II), and ozone was removed from the MSD channel subsample (KI impregnated glass wool). Preconcentration was accomplished using a combination of thermoelectric cooling $\left(-15^{\circ} \mathrm{C}\right)$ and adsorbent trapping. The preconcentration traps consisted of three stages (glass beads/Carbopack B/Carboxen 1000 for the FID channel, glass beads/Carbopack B/Carbosieves SIII for the MSD channel; all adsorbents from
Table 1. Concentrations and Figures of Merit for Measured Compounds

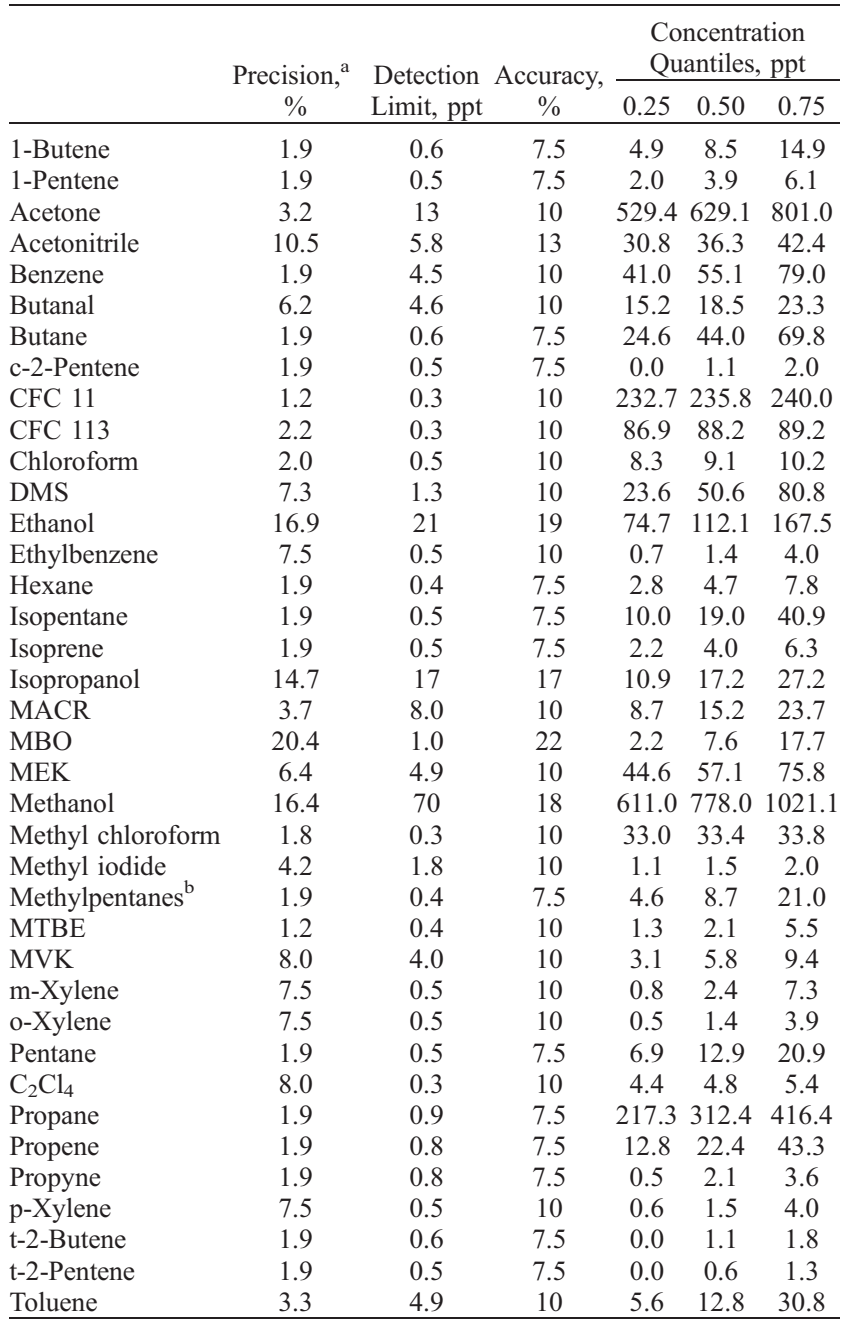

${ }^{\mathrm{a}}$ Defined as the relative standard deviation of the calibration fit residuals.

${ }^{\mathrm{b}}$ The sum of 2-methylpentane and 3-methylpentane, which coelute.

Supelco), held in place by DMCS-treated glass wool (Alltech Associates) in a $9 \mathrm{~cm}$ long, $0.1 \mathrm{~cm}$ ID fused silica-lined stainless steel tube (Restek Corp.). Samples were injected into the GC by rapidly heating the trap assemblies to $200^{\circ} \mathrm{C}$. The instrument was calibrated several times daily by dynamic dilution of low ppm level standards (Scott-Marrin Inc. and Apel-Riemer Environmental Inc.) into zero air to simulate ambient level mixing ratios. Zero air was generated by flowing ambient air over a bed of platinum heated to $370^{\circ} \mathrm{C}$ (Daniel Riemer, University of Miami, personal communication), and was analyzed daily to check for blank problems and contamination for all measured compounds. Precision, accuracy and detection limits for measured compounds, along with the $0.25,0.50$ and 0.75 quantiles of the data, are given in Table 1.

[6] Two independent high time resolution measurements of aerosol chemical composition were made, using an Aerodyne aerosol mass spectrometer (AMS, Aerodyne Re-search Inc.) [Jimenez et al., 2003; Allan et al., 2003] and a 
particle-into-liquid sampler (PILS) [Weber et al., 2001; Orsini et al., 2003]. The PILS system was operated downstream of an impactor with a $1 \mu \mathrm{m}$ cutoff (at $55 \% \mathrm{RH}$ ), whereas the AMS sampled particles smaller than about $2 \mu \mathrm{m}$. However, particles greater than $1 \mu \mathrm{m}$ were sampled with a reduced efficiency due to limitations of the aerodynamic lens [Jayne et al., 2000; Zhang et al., 2002]. Since the AMS and PILS were not configured to sample the same portion of the ambient aerosol, slightly differing results are to be expected. Particle number density $(7 \mathrm{~nm}-2.5 \mu \mathrm{m})$ was measured using a condensation particle counter (CPC, model 3022a, TSI Inc.).

[7] $\mathrm{NO}_{\mathrm{y}}$ was measured by conversion to $\mathrm{NO}$ on a heated $\left(325^{\circ} \mathrm{C}\right)$ gold catalyst using $\mathrm{H}_{2}$ as the reductant gas, followed by $\mathrm{NO}-\mathrm{O}_{3}$ chemiluminescence. $\mathrm{NO}_{\mathrm{y}}$ was calibrated via standard addition of $\mathrm{NO}_{2}$, generated by gas-phase titration of $\mathrm{NO}\left(5 \mathrm{ppm}\right.$ in $\mathrm{N}_{2}$; Scott-Marrin Inc.) with $\mathrm{O}_{3}$. Conversion efficiency for $\mathrm{NO}_{2}$ was determined via standard addition of NO without titration. Periodic conversion tests using $\mathrm{HNO}_{3}$ from a permeation device were also conducted. Data were collected at $1 \mathrm{~Hz}$ and averaged to 1 hour intervals.

[8] Radon was measured with a dual-flow loop, two-filter radon detector [Whittlestone and Zahorowski, 1998]. CO was measured by gas filter correlation, nondispersive infrared absorption (TEI 48C). Ozone was measured using a UV photometric $\mathrm{O}_{3}$ analyzer (Dasibi 1008-RS). Incoming photosynthetically active radation (PAR) was measured with LI-190SZ Quantum Sensor (Li-Cor Inc.). Wind speed and direction were monitored with a propeller wind monitor (R.M. Young Co.) mounted on a $3 \mathrm{~m}$ tower on top of the laboratory container, and ambient air temperature was measured using an HMP45C Temperature and $\mathrm{RH}$ probe (Campbell Scientific Inc.).

\section{Results and Discussion}

\subsection{Factor Analysis}

\subsubsection{Factor Analysis of VOC Data Set}

[9] Factor analysis provides a useful framework for synthesizing and interpreting the VOC data set. Observed variables, in this case species concentrations, are grouped into subsets, or factors, based on the strength of their intercorrelation. Each factor is a linear combination of the observed variables, and in theory, represents the underlying processes which cause certain species to behave similarly. The strength of association between variables and factors is described by a loading matrix, with 1 being the maximum possible loading on each factor. The data set is thus statistically ordered according to the dominant correlations, producing subsets of species whose changes in concentration are in theory predominantly driven by the same process. This can occur because of emission from common or collocated sources (e.g., anthropogenic, biogenic, photochemical) or because of a similar dependence on some other process (e.g., boundary layer dynamics or seasonal changes in $\mathrm{OH}$ ). Prior knowledge of source types for the dominant compounds can then be used to define source categories impacting the whole data set.

[10] Factor analysis was performed on the VOC and trace gas data set using Principal Components Extraction and Varimax orthogonal rotation (S-Plus 6.1, Insightful Corp.;
Table 2. Factor Analysis Results

\begin{tabular}{|c|c|c|c|c|c|}
\hline \multirow[b]{2}{*}{ Compound } & \multicolumn{5}{|c|}{ Loadings $^{\mathrm{a}}$} \\
\hline & Factor 1 & Factor 2 & Factor 3 & Factor 4 & Factor 5 \\
\hline 1-Butene & & 0.80 & & & \\
\hline 1-Pentene & & 0.79 & & & \\
\hline${ }^{222} \mathrm{Rn}$ & & & & 0.61 & \\
\hline Acetaldehyde & & 0.70 & & & \\
\hline Acetone & & 0.85 & & & \\
\hline Acetonitrile & & & & -0.59 & \\
\hline Benzene & & & 0.83 & & \\
\hline Butanal & & 0.79 & & & \\
\hline Butane & & & 0.80 & & \\
\hline c-2-Pentene & 0.55 & & & & \\
\hline Chloroform & & & 0.51 & 0.53 & \\
\hline $\mathrm{CO}$ & & & 0.84 & & \\
\hline $\mathrm{CO}_{2}$ & 0.56 & & & 0.60 & \\
\hline Ethanol & & 0.55 & & & \\
\hline Ethylbenzene & 0.85 & & & & \\
\hline Hexane & 0.79 & & & & \\
\hline Isopentane & 0.87 & & & & \\
\hline Isoprene & & & & & 0.77 \\
\hline Isopropanol & & 0.53 & & & \\
\hline MACR & & 0.81 & & & \\
\hline MBO & & & & & 0.80 \\
\hline MEK & & 0.78 & & & \\
\hline Methanol & & 0.62 & & & \\
\hline Methylpentanes ${ }^{\mathrm{b}}$ & 0.85 & & & & \\
\hline MTBE & 0.88 & & & & \\
\hline MVK & & 0.67 & & & \\
\hline m-Xylene & 0.91 & & & & \\
\hline $\mathrm{O}_{3}$ & & & & -0.72 & \\
\hline o-Xylene & 0.91 & & & & \\
\hline Pentane & 0.75 & & & & \\
\hline $\mathrm{C}_{2} \mathrm{Cl}_{4}$ & & & 0.73 & & \\
\hline Propane & & & 0.57 & & \\
\hline Propene & 0.71 & & & & \\
\hline Propyne & 0.63 & & & & \\
\hline p-Xylene & 0.90 & & & & \\
\hline $\mathrm{t}$-2-Butene & & 0.65 & & & \\
\hline $\mathrm{t}$-2-Pentene & & 0.60 & & & \\
\hline Toluene & 0.82 & & & & \\
\hline \multicolumn{6}{|c|}{ Importance of factors } \\
\hline Proportion of $\sigma^{2}$ & 0.28 & 0.20 & 0.13 & 0.07 & 0.06 \\
\hline Cumulative $\sigma^{2}$ & 0.28 & 0.48 & 0.61 & 0.68 & 0.74 \\
\hline
\end{tabular}

${ }^{a}$ Loadings of magnitude $<0.5$ omitted.

${ }^{\mathrm{b}}$ The sum of 2-methylpentane and 3-methylpentane.

results shown in Table 2). Compounds having $>5 \%$ missing data or $>5 \%$ zero measured concentration were not used. Five factors were extracted which accounted for a total of $74 \%$ of the variance in the data set. The analysis was limited to five factors because the addition of a sixth factor did not explain a significant portion of the variance (3\%). Loadings of magnitude less than 0.5 are not shown as they are not considered significant for this analysis.

[11] Compounds not loading significantly on any of the five factors (dimethylsulfide, methyl iodide, methyl chloroform, CFC 11 and CFC 113) are also omitted from Table 2. Methyl iodide was only present above the detection limit of $1.8 \mathrm{ppt}$ in $29 \%$ of the observations. The fact that this compound did not group with any of the subsets in the factor analysis is presumably because any variability in the ambient concentrations was too small to be accurately resolved. Production and use of methyl chloroform, CFC 11 and CFC 113 has been banned since 1996 in developed countries under the Montreal Protocol. Concentrations of 
these compounds exhibited little variability at Trinidad Head, with no detectable correlation with other tracers of anthropogenic pollution. The fact that dimethylsulfide did not load with any other compounds suggests that if oceanic emissions were important for the other species included in the analysis then they had different source regions and/or emission mechanisms than did DMS.

[12] Factor 1, representing 28\% of the variance in the data set, is dominated by short-lived anthropogenic compounds such as the xylenes, methyl-t-butyl-ether (MTBE) and the $\mathrm{C}_{5}-\mathrm{C}_{6}$ alkanes. Because of their short residence time in the atmosphere (less than a few days at $\mathrm{OH}=1 \times$ $10^{6} \mathrm{molec} / \mathrm{cm}^{3}$ ), background levels of these species are very low. The variance in their measured concentrations at Trinidad Head was driven largely by episodes of offshore wind, and stagnant nighttime conditions, when the effects of local continental emissions could be observed. We therefore interpret this factor as representing the influence of local anthropogenic emissions, predominantly from fossil fuel use.

[13] Factor 2 accounts for a further $20 \%$ of the variance and is associated with oxygenated compounds, such as acetone and methyl ethyl ketone (MEK), as well as some of the alkenes such as 1-butene and 1-pentene. The oxygenated VOCs (OVOCs) associated with factor 2 can have a variety of sources, including photochemical production from natural or anthropogenic precursors, emission from terrestrial ecosystems, and direct anthropogenic sources such as incomplete combustion and evaporative emissions [Lamanna and Goldstein, 1999; Goldan et al., 1995; Goldstein and Schade, 2000]. There is also evidence that oceanic emissions can be a source of some OVOCs [Gschwend et al., 1982; Nuccio et al., 1995; Zhou and Mopper, 1997; Singh et al., 2001; Heikes et al., 2002; Jacob et al., 2002]. The alkenes that load on factor 2 can be combustion derived, although oceanic [Plass-Dülmer et al., 1995] and terrestrial biogenic [Goldstein et al., 1996] emission sources are also known to be significant. The fact that these two classes of compounds are grouped together in factor 2 is likely due to common or collocated sources that are distinct from the fossil fuel derived direct emissions dominating factor 1 .

[14] Factor 3 represents another $13 \%$ of the cumulative variance, and, like factor 1, is associated with species $(\mathrm{CO}$, benzene, butane, perchloroethylene, propane, chloroform) of predominantly anthropogenic origin. However, these are longer-lived compounds (residence times range from approximately 5 days for butane to $3-4$ months for perchloroethylene and chloroform at an $\mathrm{OH}$ concentration of $1 \times$ $10^{6} \mathrm{molec} / \mathrm{cm}^{3}$ ) which have significant background levels. Consequently, the relative impact of short-term stagnant or offshore flow conditions on observed concentrations at Trinidad Head was less important than for factor 1 compounds. More significant for factor 3 compounds was the fact that this study was carried out during spring, a time of year when $\mathrm{OH}$ concentrations at this latitude are increasing rapidly in response to seasonally increasing levels of incoming solar radiation. As a result, the background concentrations of all compounds loading significantly on factor 3 underwent substantial decreases during the course of the study, consistent with published observations of VOC seasonal cycles in the northern hemisphere [Goldstein et al., 1995; Jobson et al., 1994; Swanson et al., 2003]. This seasonal change in background concentrations is further analyzed in section 3.1.2.

[15] Factor 4, accounting for $7 \%$ of the cumulative variance, is associated with compounds whose concentrations at the site were largely dictated by local atmospheric mixing processes. Stable conditions with limited vertical or horizontal mixing led to elevated concentrations of radon as local emissions from soils accumulated within a smaller mixing volume. The same was true for carbon dioxide, as stable conditions generally occurred at night when the terrestrial biosphere acts as a net source for $\mathrm{CO}_{2}$. Conversely, periods of limited mixing in general led to low ozone levels, owing to ozone loss near the ground due mainly to surface deposition. Ozone sondes launched daily from the site confirmed that higher ozone was observed at the ground site only during times of strong atmospheric mixing. We interpret factor 4 as representing the effects of local meteorology and vertical mixing.

[16] Recent work [Warneke and de Gouw, 2001; de Laat et al., 2001; de Gouw et al., 2003] has demonstrated the existence of a significant oceanic sink of acetonitrile, particularly in coastal and upwelling regions. The association of acetonitrile with factor 4 is likely due to this process, with oceanic uptake reducing atmospheric concentrations more strongly under stable conditions.

[17] The only compounds that loaded significantly on factor 5 were isoprene and 2-methyl-3-buten-2-ol (MBO), both highly reactive biogenic compounds that are emitted from terrestrial ecosystems in a light and temperaturedependent manner. Factor 5 explained $6 \%$ of the data set variance and is taken to signify local terrestrial biogenic emissions.

[18] These five factors characterize the dominant processes determining atmospheric composition at Trinidad Head.

\subsubsection{Seasonal Changes in Background Concentrations}

[19] Compounds with residence times longer than a few days and whose main loss mechanism was $\mathrm{OH}$ chemistry (factor 3) showed evidence of seasonally changing background concentrations. Factor 1 compounds, on the other hand, exhibited little or no change in background concentrations during the timeframe of the ITCT $2 \mathrm{~K} 2$ experiment. These more reactive compounds are likely too short-lived to build up significantly in the troposphere, even in the winter when $\mathrm{OH}$ is lower.

[20] For atmospheric constituents that do not undergo observable changes in background concentrations due to $\mathrm{OH}$ chemistry, any relationship with longer-lived anthropogenic VOCs will be obscured by the strong seasonal decrease that occurs during springtime in the northern hemisphere.

[21] To remove this effect we detrended the factor 3 compounds as follows. The seasonal cycle in $\mathrm{OH}$ concentration at northern midlatitudes can be approximated as

$$
[\mathrm{OH}]=7 \times 10^{5}\left[1-\beta \cos \left(\frac{2 \pi \mathrm{d}}{365}\right)\right]
$$

with $[\mathrm{OH}]$ in molec $/ \mathrm{cm}^{3}$ and $\mathrm{d}$ in day of year. $\beta$ is a dimensionless adjustable parameter, and $7 \times 10^{5} \mathrm{molec} / \mathrm{cm}^{3}$ 


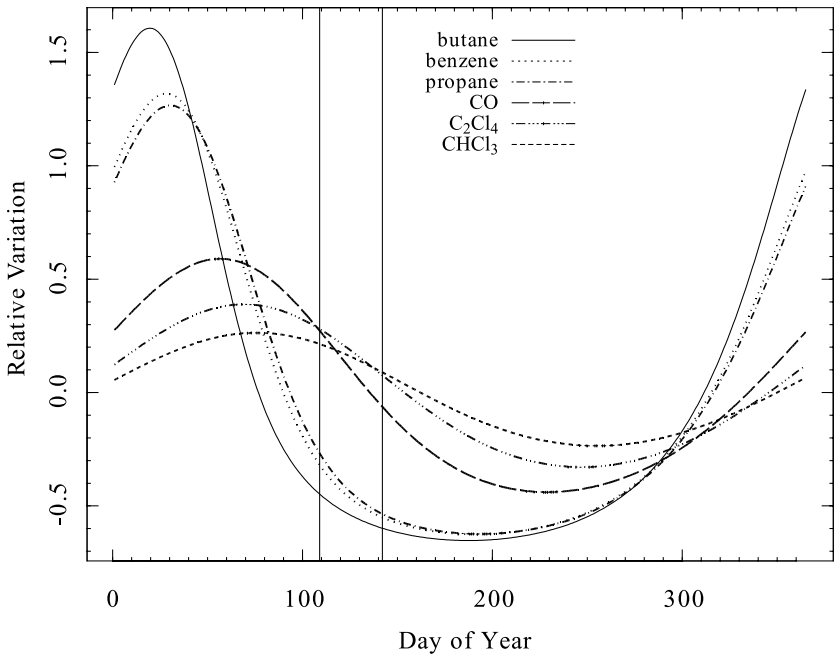

Figure 1. Modeled relative variation of selected VOCs based on seasonally changing $\mathrm{OH}$ concentrations. The vertical lines indicate the time period of the ITCT $2 \mathrm{~K} 2$ experiment.

is representative of the annual mean $\mathrm{OH}$ concentrations in northern midlatitudes [Goldstein et al., 1995; Spivakovsky et al., 1990]. The change in concentration of species X $\left(\mathrm{molec} / \mathrm{cm}^{3}\right)$ having rate constant for reaction with $\mathrm{OH} \mathrm{k}_{\mathrm{X}}$ $\left(\mathrm{cm}^{3} / \mathrm{molec} \cdot \mathrm{s}\right)$ and source magnitude $\mathrm{S}_{\mathrm{X}}\left(\mathrm{molec} / \mathrm{cm}^{3} \cdot \mathrm{s}\right)$ as a function of time ( $t$, in seconds) can then be approximated by

$$
\frac{\partial[\mathrm{X}]}{\partial \mathrm{t}}=\mathrm{S}_{\mathrm{X}}-\mathrm{k}_{\mathrm{X}}[\mathrm{OH}][\mathrm{X}] .
$$

Seasonal cycles modeled in this manner for the factor 3 compounds (CO, benzene, propane, butane, $\mathrm{CHCl}_{3}$ and $\left.\mathrm{C}_{2} \mathrm{Cl}_{4}\right)$, relative to their annual mean $\left([\mathrm{X}]_{\mathrm{t}} /[\mathrm{X}]_{\mathrm{ave}}-1\right)$ are shown in Figure 1. OH rate constants were taken from Atkinson [1994] and Sander et al. [2002]. Vertical lines indicate the time period of the experiment. The modeled seasonal backgrounds were then fit to the lower envelope of the data, and detrended compound concentrations were obtained by subtracting the seasonal cycle from the observations. Results are shown in Figure 2, with the observed concentrations and modeled seasonal cycles in the left column, and the detrended values in the right column. These detrended concentrations for the factor 3 compounds are used in the following analysis.

\subsubsection{Application of Factor Analysis Results to Other} Measured Species

[22] The major processes driving the temporal behavior of other measured species can be explored using the categories defined by the factor analysis. We selected one highly-loading compound, as representative of each factor: factor 1 - isopentane (local short-lived anthropogenic emissions); factor 2 - acetone (oxygenated species, including some olefins); factor 3 - benzene (long-lived anthropogenic emissions, detrended); factor 4 - radon (local meteorological influence); and factor 5 - isoprene (local short-lived biogenic emissions). The processes underlying the temporal variability of the different factors are not independent and neither are the compounds chosen to represent each factor. Loadings for these compounds on all factors are shown in Table 3. While the five chosen compounds load on more than one factor, each is dominantly associated with one particular factor.

[23] Multiple regressions were then performed for other measured aerosol and gas species of interest using these representative compounds as independent variables. The most appropriate set of predictors for each response variable was determined using stepwise regression with Mallow's $C_{p}$ statistic as the selection criterion. The data used in this analysis are highly skewed from a normal distribution. However, transforming the data to more closely resemble a normal distribution did not significantly alter the conclusions of the regression analysis.

[24] Table 4 shows the salient results of this analysis. The relative importance of each representative compound in explaining the variability of a response variable is given by the sum of squares (expressed as a percentage of the total sum of squares of the model). The multiple $\mathrm{R}^{2}$ values for each regression are also shown, as are the $\mathrm{P}$ values for each predictor variable. The $\mathrm{P}$ value is the probability that the observed correlation between predictor and response variables could arise solely due to chance. In cases where a measure of aerosol chemical composition was available from both the AMS and PILS instruments, we employed the PILS data as there was less random noise in this data set. Employing the AMS data instead did not alter the conclusions.

[25] The total particle number density $(7 \mathrm{~nm}-2.5 \mu \mathrm{m})$ was most strongly associated with factor 3 compound benzene, representing less reactive species and the influence of longerrange transport. Isopentane also accounted for a significant portion of the variability in observed aerosol number densities, indicating that local emission sources are important contributors to the local aerosol number density budget as well. The strongest predictor of the particle-phase organics, measured using the AMS [Allan et al., 2004], was also the long-lived anthropogenic factor 3. This indicates that episodic, short-term pollution events and local meteorology, which strongly impacted factors 1 and 4, were less important for the organic aerosol mass than larger scale transport history, which drove much of the variance in factor 3 . This also suggests that the atmospheric residence time of the organic aerosol mass is longer than those associated with factor 1. Aerosol residence times are examined further in the variability-lifetime analysis in section 3.3. The factor 2 compound acetone also accounted for a significant amount of the variability in the organic aerosol, likely reflecting a common source, i.e., photochemical production of oxygenated VOCs and secondary organic aerosol. The relationship between the organic aerosol and VOCs is examined further in Allan et al. [2004].

[26] The factor 1 compound isopentane was by far the dominant predictor of gas-phase $\mathrm{NO}_{\mathrm{y}}$, demonstrating the importance of nearby sources for the local $\mathrm{NO}_{\mathrm{y}}$ budget, and suggesting a relatively short residence time for $\mathrm{NO}_{\mathrm{y}}$ in the marine boundary layer. Similarly, aerosol nitrate (PILS) was most strongly associated with factor 1 . Local meteorology (factor 4) also played a role in determining $\mathrm{NO}_{3}$ concentrations.

[27] Sulfate and ammonium (PILS) were not highly correlated with the species representing the five factors 

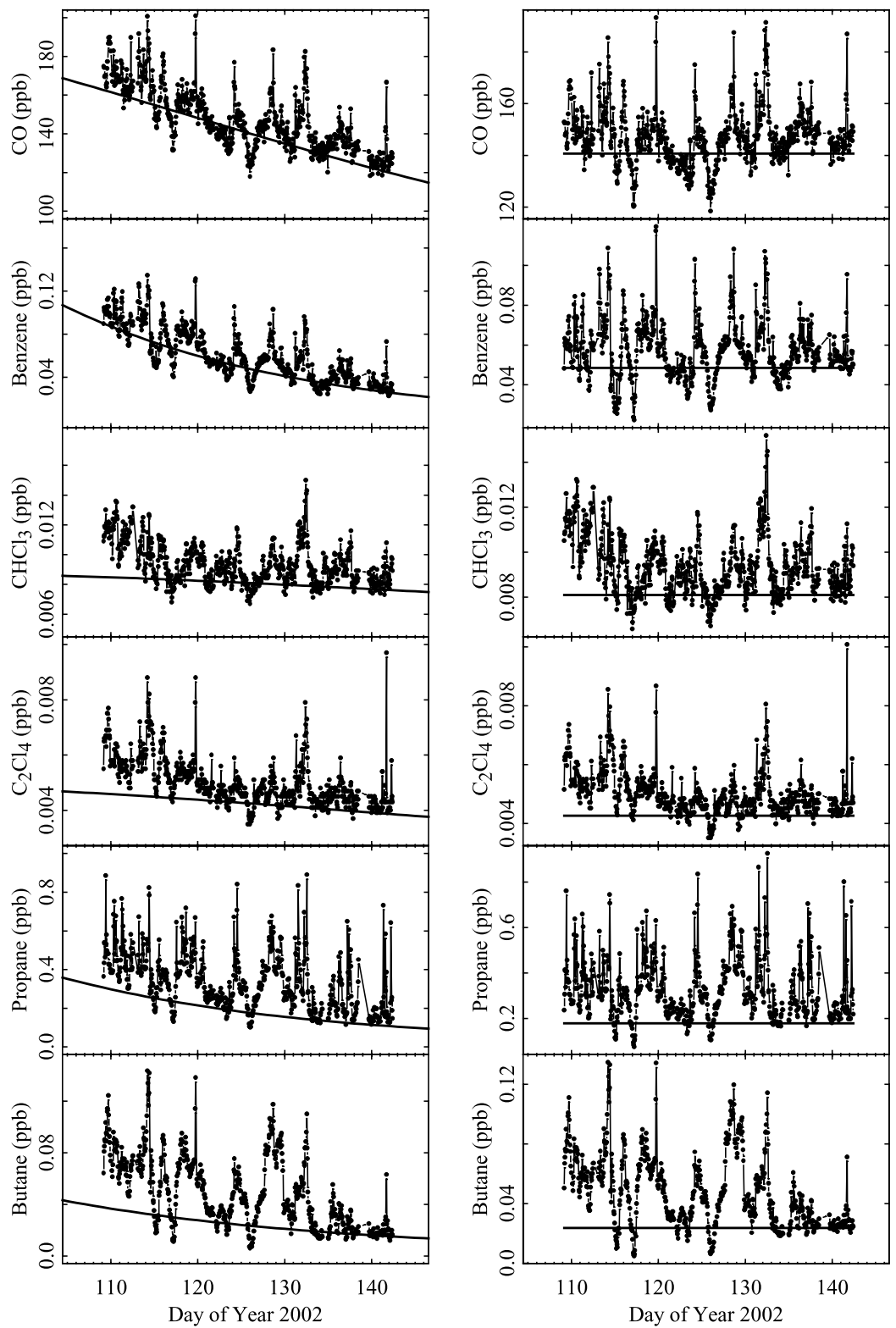

Figure 2. Concentrations of selected VOCs measured during the Trinidad Head campaign, highlighting the seasonal changes in VOC backgrounds. The left column shows the observations and modeled seasonally changing background (solid line). The right column shows the concentrations after the modeled seasonal cycle was subtracted from the data.

defined by the VOC analysis (multiple $\mathrm{R}^{2}=0.22$ and 0.38 , respectively). However, the primary predictor for both was factor 2 , the oxygenated compounds. The majority of the particulate sulfate in the measured size range at Trinidad head is likely produced via oxidation of DMS. DMS is a precursor of both sulfur dioxide, which is subsequently oxidized to sulfate, and methane sulfonic acid (MSA) (we use the abbreviation MSA to refer to both methane sulfonic acid, and methane sulfonate, the ionic form present in the aerosol phase). The ratio of MSA to non-sea-salt sulfate in aerosols has therefore been used to estimate the marine biogenic contribution to particulate sulfate [e.g., Savoie et al., 2002], although this is complicated by the fact that the relative yield of $\mathrm{SO}_{2}$ and MSA from DMS oxidation is quite variable [Bates et al., 1992; Koga and Tanaka, 1999]. The
MSA to non-sea-salt sulfate ratio in the submicron aerosol during the experiment was $0.17(0.12-0.22)$ (median and interquartile range). Savoie et al. [2002] estimate the marine biogenic MSA to non-sea-salt sulfate ratio as 0.05 at Bermuda $(32.27 \mathrm{~N})$ and 0.33 at Mace Head, Ireland $(53.32 \mathrm{~N})$, two locations which bracket Trinidad Head in

Table 3. Loadings on All Factors for Representative Species

\begin{tabular}{lccccc}
\hline & Factor 1 & Factor 2 & Factor 3 & Factor 4 & Factor 5 \\
\hline Isopentane & $\mathbf{0 . 8 7}$ & 0.23 & 0.29 & 0.19 & - \\
Acetone & 0.16 & $\mathbf{0 . 8 5}$ & 0.35 & - & - \\
Benzene & 0.31 & 0.15 & $\mathbf{0 . 8 3}$ & 0.19 & 0.20 \\
${ }^{222} \mathrm{Rn}$ & 0.34 & 0.31 & 0.36 & $\mathbf{0 . 6 1}$ & - \\
Isoprene & 0.26 & 0.10 & 0.11 & - & $\mathbf{0 . 7 7}$ \\
\hline
\end{tabular}


Table 4. Multiple Regression Results

\begin{tabular}{lccc}
\hline & $\begin{array}{c}\text { Multiple } \\
\mathrm{R}^{2}\end{array}$ & $\begin{array}{c}\text { Sum of Squares } \\
\text { (\% of total) }\end{array}$ & $\mathrm{P}$ \\
\hline Aerosol organics & 0.38 & & \\
Benzene (factor 3) & & 69.6 & 0.0000 \\
Acetone (factor 2) & & 26.6 & 0.0000 \\
$\quad$ Radon (factor 4) & 0.44 & 3.8 & 0.0335 \\
Particle number & & 48.1 & \\
Benzene (factor 3) & & 30.8 & 0.0000 \\
Isopentane (factor 1) & & 21.1 & 0.0000 \\
Isoprene (factor 5) & 0.63 & & \\
Aerosol nitrate & & 95.4 & 0.00000 \\
Isopentane (factor 1) & & 4.6 & 0.0000 \\
Radon (factor 4) & 0.65 & 91.4 & 0.0000 \\
NO & & 8.6 & 0.0000 \\
Isopentane (factor 1) & & 67.6 & 0.0000 \\
Benzene (factor 3) & 0.22 & 17.0 & 0.0000 \\
Aerosol sulfate & & 11.2 & 0.0004 \\
Acetone (factor 2) & & 4.2 & 0.0283 \\
Isoprene (factor 5) & & & \\
Isopentane (factor 1) & & 64.5 & 0.0000 \\
Benzene (factor 3) & 0.38 & 19.1 & 0.0000 \\
Aerosol ammonium & & 11.4 & 0.0000 \\
Acetone (factor 2) & & 3.2 & 0.0120 \\
Isopentane (factor 1) & & & \\
Benzene (factor 3) & & & \\
Radon (factor 4) & & & \\
\hline
\end{tabular}

latitude. We interpret the relatively high ratios at Trinidad Head as evidence that DMS oxidation is a primary source of submicron sulfate. There may also be a small contribution to the ambient submicron sulfate from the tail end of the coarse sea salt aerosol.

[28] Ammonia, an intermediate in marine nutrient cycling, is emitted to the atmosphere in substantial quantities from productive surface waters [Quinn et al., 1988; Liss and Galloway, 1993; Dentener and Crutzen, 1994; Jickells et al., 2003], where it quickly reacts with acidic aerosol to yield particulate ammonium. The correlation of sulfate and ammonium with factor 2 may indicate a significant oceanic source for some oxygenated and olefinic VOCs. In addition, the fact that sulfate and many oxygenated VOCs can be produced in the atmosphere from photochemical oxidation of gas-phase precursors is likely contributing to this correlation. Ammonium does not have a photochemical source but is in general associated with particulate sulfate as ammonium sulfate.

\subsection{Inflow Chemical Characteristics}

[29] Quantifying the inflow boundary conditions for the chemical composition of air entering North America from the Pacific Ocean requires an effective method of filtering out observations that have been impacted by recent continental emissions from North America itself. Factor $1 \mathrm{com}-$ pounds provide convenient tracers for filtering out these local influences. We employ MTBE for this purpose as it has a well-defined anthropogenic source (primarily from automotive emissions), a short atmospheric residence time ( $\sim 4$ days at $1 \times 10^{6}$ molec $\left./ \mathrm{cm}^{3} \mathrm{OH}\right)$ and is detected with high sensitivity and precision using our analytical system (detection limit $=0.4 \mathrm{ppt}$; RSD precision $=1.2 \%$ ).

[30] MTBE concentrations at Trinidad Head exhibited a strong diurnal pattern (Figure 3). Concentrations were lowest in the afternoon, with a minimum between 13:00 and 19:00 PST of $1.2(0.9-1.7)$ ppt (median and interquar- tile range), and a maximum in the early morning between 05:00 and 10:00 PST of 4.6 (2.2-8.8) ppt (median and interquartile range). The observed behavior was driven by the dominant wind patterns, with strong daytime winds out of the north-west (off the ocean), and weaker and more variable winds at night (Figure 3). As a result, the air masses sampled during the day were typically of marine origin with little recent continental influence, whereas at night the effects of recent continental emissions (e.g., elevated levels of short-lived anthropogenic and terrestrial biogenic species) were more commonly observed.

[31] MTBE concentration, plotted on standard cumulative probability axes, is shown in Figure 4a, with lines drawn through the $0.5,0.6,0.7$ and 0.8 quantiles of the data. There was a clear separation between clean background and more polluted air, and we take the 0.6 quantile, or $3 \mathrm{ppt}$, as the approximate inflection point of the curve and the threshold for significant recent influence from North American continental emissions. Using the 0.6 quantile of any of the other five highest loading factor 1 compounds instead changes the fraction of below-threshold values by less than $10 \%$.

[32] Figure $4 \mathrm{~b}$ shows a polar plot of MTBE concentration vs. wind direction, with Figure $4 \mathrm{c}$ showing only data below

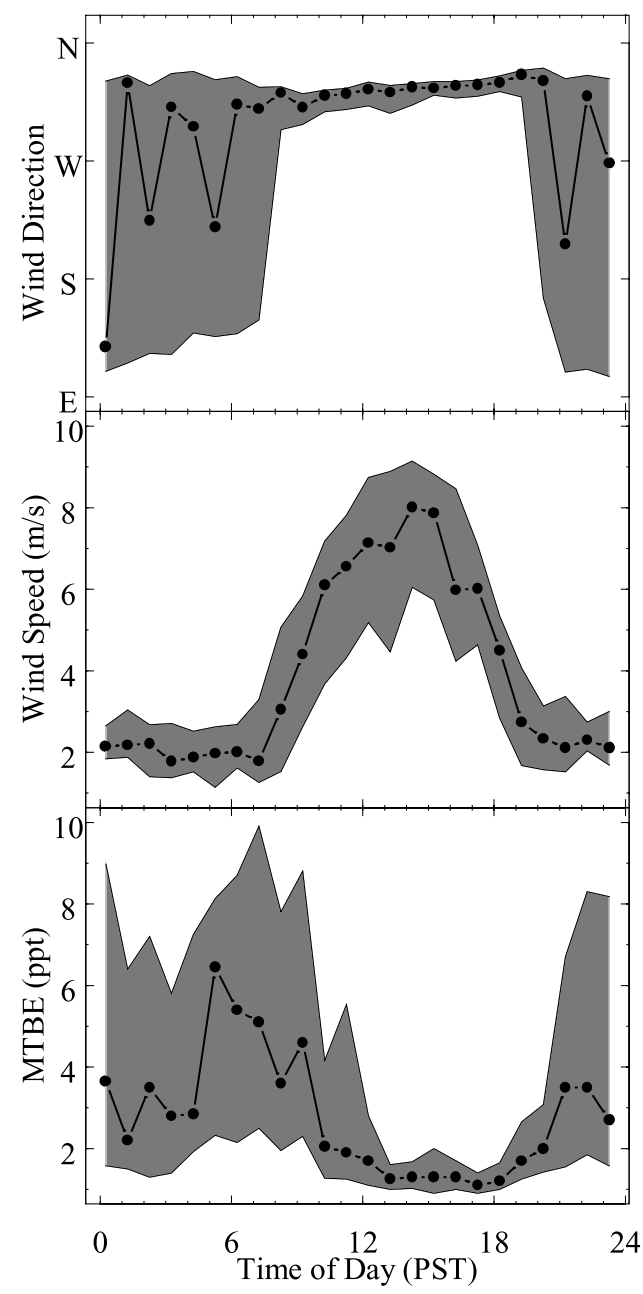

Figure 3. Median diurnal patterns in wind direction, wind speed and MTBE concentrations at Trinidad Head. The shaded regions bound the interquartile range. 

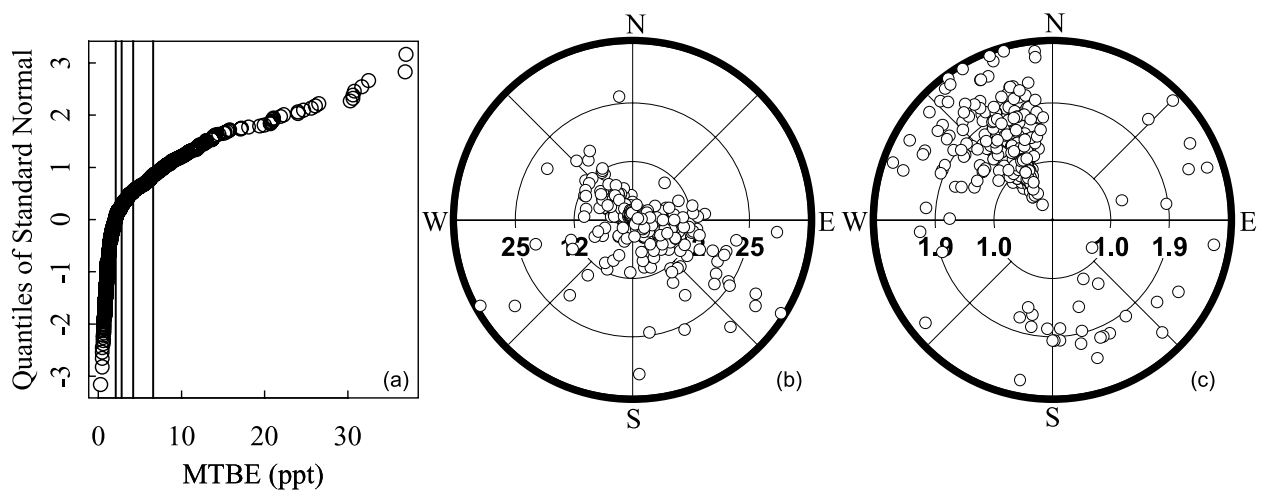

Figure 4. (a) Quantile plot of MTBE concentrations at Trinidad Head. Vertical lines indicate the 0.5, 0.6, 0.7 and 0.8 quantiles of the data. (b) MTBE concentration (ppt) versus wind direction (all data).

(c) MTBE concentration (ppt) versus wind direction, showing only values less than $3 \mathrm{ppt}$.

the 3 ppt threshold. Air masses having MTBE $<3$ ppt were predominantly associated with winds from the northwest. The MTBE filter excludes a large amount of data associated with onshore winds. Chemical tracers such as MTBE are particularly useful in this situation, since instantaneous wind speeds do not necessarily provide an accurate indicator of air mass history, and back-trajectory analysis is typically less certain near the surface than aloft.

[33] The effect of the $3 \mathrm{ppt}$ MTBE filter is illustrated in Figure 5, which shows timelines of benzene and o-xylene, two combustion-derived species with significantly different atmospheric residence times (10 days and 20 hours respectively at $1 \times 10^{6} \mathrm{molec} / \mathrm{cm}^{3} \mathrm{OH}$ ), segregated according to MTBE. In both cases, the high-concentration episodes are excluded using the 3 ppt MTBE cutoff.

[34] We now use the MTBE filter to examine the composition and chemical characteristics of air at Trinidad
Head. One simple index of the chemical reactivity of an air mass is the total $\mathrm{OH}$ reactivity for measured compounds, defined as

$$
\mathrm{OH} \text { Reactivity }=\sum_{X} \mathrm{k}_{\mathrm{X}}[\mathrm{X}],
$$

where $\mathrm{k}_{\mathrm{X}}$ is the rate constant for reaction of species $\mathrm{X}$ with the $\mathrm{OH}$ radical, and $[\mathrm{X}]$ is the concentration of species $\mathrm{X}$. The $\mathrm{OH}$ reactivity provides information about regional $\mathrm{HO}_{\mathrm{x}}$ radical cycling, and the dominant compounds or classes of compounds competing for $\mathrm{OH}$ radicals.

[35] CO was the primary contributor to the total measured $\mathrm{OH}$ reactivity at all times (Figure 6). Concentrations of $\mathrm{CO}$ were enhanced during periods when discernable local emissions were present, but its relative importance was greater during "clean" conditions (MTBE $<3$ ppt).

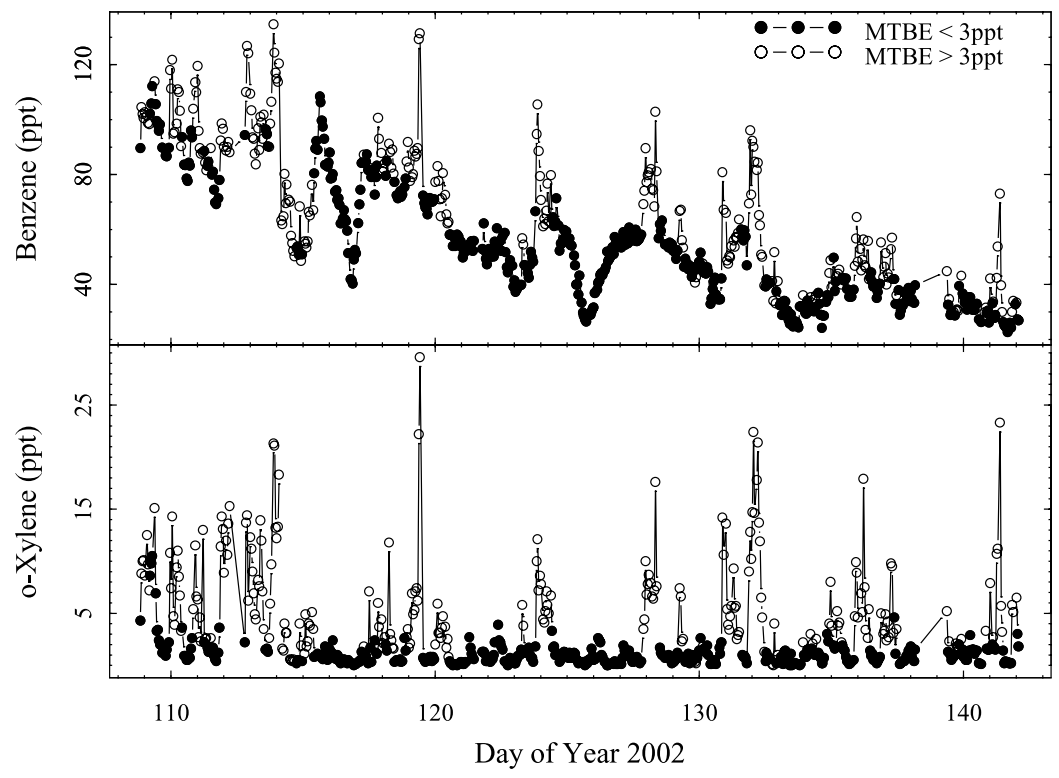

Figure 5. Timelines of benzene and o-xylene concentrations, showing the effect of the 3 ppt MTBE filter. In both cases concentrations significantly above background are excluded using the 3 ppt MTBE cutoff. 


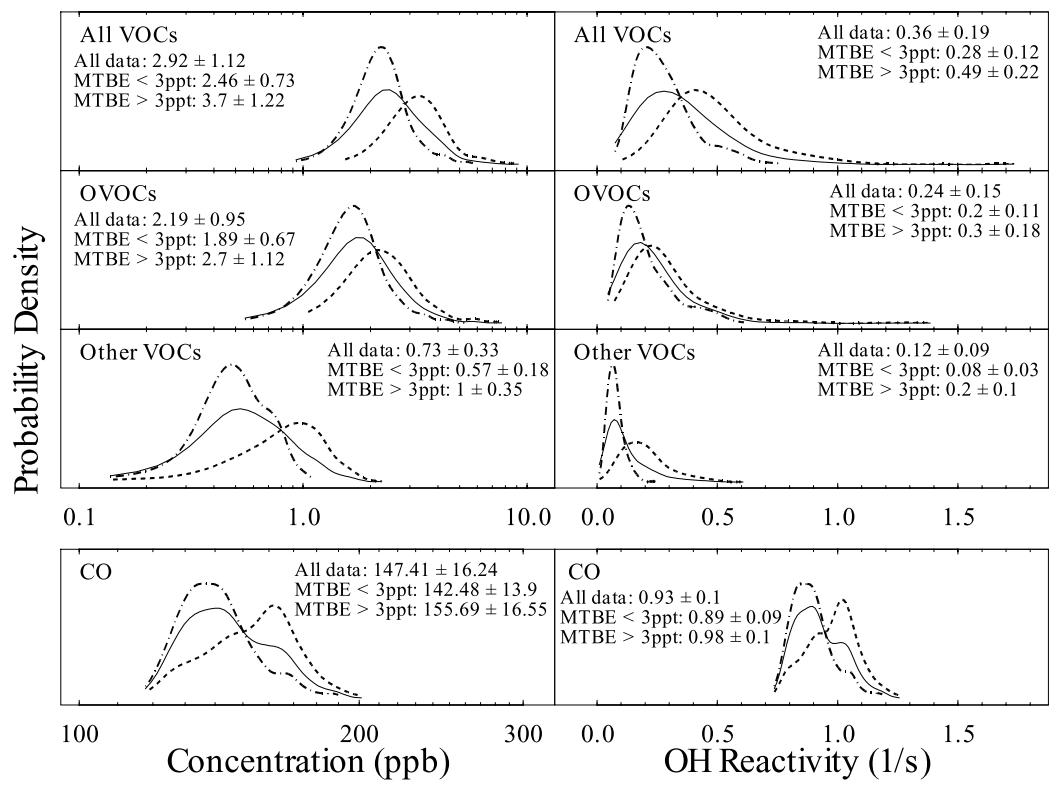

Figure 6. Probability density curves of (left) concentrations and (right) $\mathrm{OH}$ reactivity for different VOC classes and for $\mathrm{CO}$. The solid, dash-dot and dashed line show probability density curves for all the data, for times when $\mathrm{MTBE}<3 \mathrm{ppt}$, and for times when MTBE $>3 \mathrm{ppt}$, respectively. The mean quantity \pm 1 standard deviation is given for each case. Note the log scale for plots in the left column.

[36] When data containing significant influence from local emissions were filtered out, the total observed VOC abundance was $2.46 \pm 0.73 \mathrm{ppb}$ (mean $\pm \mathrm{SD}$ ) during the experiment (Figure 6), corresponding to a $\mathrm{VOC} \mathrm{OH}$ reactivity of $0.28 \pm 0.12 \mathrm{~s}^{-1}$ (mean $\pm \mathrm{SD}$ ). Note that formaldehyde and the $\mathrm{C}_{2}$ compounds ethane, ethene and ethyne were not measured. On the basis of airborne observations of the $\mathrm{C}_{2}$ hydrocarbons species obtained during ITCT 2K2 (Elliot Atlas, NCAR, personal communication) and published observations of formaldehyde in the marine boundary layer [Fried et al., 2002, 2003], we estimate that inclusion of these compounds would increase the VOC abundance and reactivity at Trinidad Head to approximately $4.3 \mathrm{ppb}$ and $0.4 \mathrm{~s}^{-1}$, respectively. By contrast, the $\mathrm{CO} \mathrm{OH}$ reactivity was $0.89 \pm 0.09 \mathrm{~s}^{-1}$ (mean $\left.\pm \mathrm{SD}\right)$ during these clean periods.

[37] Oxygenated VOCs accounted for, on average, 77\% of the measured VOC abundance $(1.89 \pm 0.67 \mathrm{ppb}$; mean \pm SD) and $70 \%$ of the measured VOC OH reactivity $(0.20 \pm$ $0.11 \mathrm{~s}^{-1}$; mean $\pm \mathrm{SD}$ ) during these clean conditions. Including the effects of the $\mathrm{C}_{2}$ hydrocarbons and formaldehyde would decrease the relative contribution of the oxygenated VOCs to the total VOC abundance, but would increase their relative contribution to the total $\mathrm{VOC} \mathrm{OH}$ reactivity. Oxygenated species were thus the dominant VOC compound class measured at Trinidad Head, both in terms of abundance and reactivity, as has been observed in other unpolluted marine areas [Singh et al., 2001]. As with CO, while concentrations of OVOCs were higher during periods when local emissions were significant, their relative importance was highest during clean conditions.

[38] At no time during this campaign were elevated concentrations of VOCs observed that could be definitively associated with emissions originating in Asia. In addition, emissions of methyl chloroform, CFC 11 and CFC 113 were observed in plumes leaving Asia during the period of our measurements [Palmer et al., 2003], yet these species did not have observable enhancements at Trinidad Head. This strongly implies that Asian pollution plumes did not coherently impact Trinidad Head during the field campaign. For a full discussion of this issue see Goldstein et al. [2004].

\subsection{Variability-Lifetime Relationship}

[39] In this section we quantify the VOC lifetime-variability dependence at Trinidad Head, and use it to estimate the average $\mathrm{OH}$ concentration for the study period and to infer atmospheric residence times for aerosol species measured during the field campaign.

[40] The idea that trace gas variability could serve as a useful diagnostic for estimating atmospheric residence times was first suggested by Junge [1963]. Subsequent authors have attempted to define the dependence of variability on lifetime both analytically and empirically [Gibbs and Slinn, 1973; Junge, 1974; Jaenicke, 1982; Hamrud, 1983; Slinn, 1988; Jobson et al., 1998, 1999].

[41] Jobson et al. [1998, 1999] examined the connection between trace gas mixing ratio and atmospheric lifetime in the context of regional non-methane hydrocarbon and halocarbon data sets. Using the standard deviation of the natural $\log$ arithm of the mixing ratio $\left(\mathrm{s}_{\ln \mathrm{X}}\right)$ as a variability index, they found that for a range of different sampling locales, including continental, coastal, remote oceanic, and stratospheric sites, variability followed a power law dependence on lifetime,

$$
\mathrm{S}_{\ln \mathrm{X}}=\mathrm{A} \tau^{-\mathrm{b}} .
$$

The parameter $b$ ranged from approximately zero in some source-dominated urban regions, to close to unity (the chemical kinetic limit) in regions extremely remote from sources, such as the stratosphere and in the arctic [Jobson et al., 1999]. Thus in areas where concentration gradients are determined primarily by chemical loss rather than source 
variability and mixing, a strong dependence of trace gas variability on atmospheric lifetime is observed. Closer to source regions, source variability and mixing of air masses of different ages strongly influence trace gas concentrations, and the variability dependence on atmospheric lifetime is weakened. The Jobson form of the variability-lifetime relationship has since been employed to assess data set quality, to explore the possibility of anomalous sources or sinks for outlying compounds, and to estimate species lifetimes and radical concentrations [Jobson et al., 1999; Williams et al., 2000; Karl et al., 2001; Colman et al., 1998; Williams et al., 2001; Warneke and de Gouw, 2001; Williams et al., 2002].

[42] We use this approach to define the variability-lifetime relationship for the Trinidad Head VOC data. Lifetimes for all measured VOCs are calculated according to

$$
\tau=\frac{1}{\mathrm{k}_{\mathrm{OH}}[\mathrm{OH}]+\mathrm{k}_{\mathrm{O} 3}\left[\mathrm{O}_{3}\right]+\mathrm{J}}
$$

where $\mathrm{k}_{\mathrm{OH}}$ and $\mathrm{k}_{\mathrm{O} 3}$ are the rate constants for reaction with $\mathrm{OH}$ and $\mathrm{O}_{3}$ [Atkinson, 1994; Sander et al., 2002], and $\mathrm{J}$ is the photolysis rate. Rate constants were calculated using temperatures observed at Trinidad Head. Ozone concentrations were measured on-site. $\mathrm{J}$ values for relevant species (e.g., acetone) were calculated using the UCAR Tropospheric Ultraviolet and Visible (TUV) radiation model. The $\mathrm{OH}$ concentration is unknown, and represents the average $\mathrm{OH}$ encountered by air masses in transit to the Trinidad Head site during the study. For all compounds used in this analysis, $\mathrm{OH}$ chemistry is the dominant loss process. Calculated values of $\tau$ and the parameter $\mathrm{A}$ are thus sensitive to the assumed average $\mathrm{OH}$ concentration, whereas the parameter $\mathrm{b}$ and the correlation between $\mathrm{s}_{\operatorname{lnX}}$ and $\tau$ are fairly insensitive to $[\mathrm{OH}]$.

\subsubsection{VOC Variability-Lifetime Dependence}

[43] Figure 7 shows a plot of $s_{\operatorname{lnX}}$ vs. $\tau$ for the Trinidad Head VOC data. The derivation of the $\mathrm{OH}$ concentration employed for the lifetime calculations is described in the following section. There is a consistent $\mathrm{S}_{\ln X}-\tau$ dependence for all compounds (with the exception of acetonitrile, which was not included in the regression and is discussed below), across a wide range of lifetimes $\left(10^{0}-10^{4}\right.$ days) and source types. A fit of equation (4) to the data, indicated by the solid line, yields $\mathrm{s}_{\ln X}=(1.55 \pm 0.17) \tau^{(-0.44 \pm 0.03)}$, with $\mathrm{r}^{2}=0.98$. Error limits represent $95 \%$ confidence intervals. Compounds with lifetimes shorter than 1 day were found to fall below the curve, as has been observed in other data sets [Jobson et al., 1998], and were not included in the regression. Interestingly, filtering out local influences using the 3 ppt MTBE cutoff (not shown) extends the validity of the general $s_{\ln x}-\tau$ fit down to lifetimes of 12 hours or greater. This suggests that local source variability is at least partly responsible for the observed falloff at very short lifetimes. Lifetimes for the longest-lived compounds (acetonitrile, Freons and methylchloroform) were taken as the global mean values rather than using the calculated local $\mathrm{OH}$ concentration.

[44] The A and b parameters are indicative of the chemical and dynamic history of sampled air masses, and can be expected to display substantial seasonal as well as geographic variation [Jobson et al., 1999; Johnston et al.,

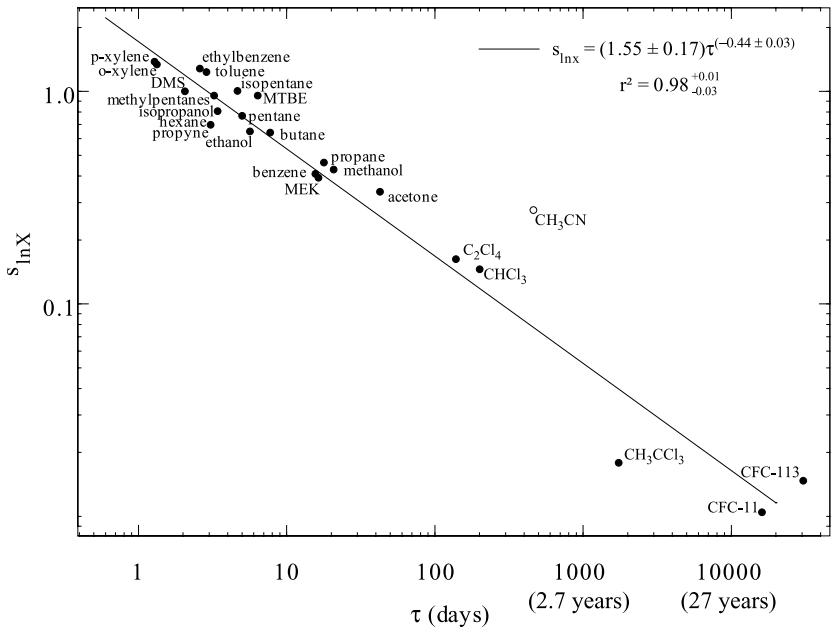

Figure 7. Variability-lifetime relationship for the VOCs. Lifetimes were calculated using an $\mathrm{OH}$ concentration of $6.1 \times 10^{5} \mathrm{molec} / \mathrm{cm}^{3}$, derived from the observed variability in radon concentrations (see section 3.3.2.).

2002]. However, the $s_{\ln X}-\tau$ fit obtained in this study is consistent with results from other experiments in similar locations. For example, Jobson et al. [1999] report fit results of $1.61 \tau^{-0.44}$ and $1.91 \tau^{-0.40}$ for data collected at Sable Island and shipboard during NARE in August 1993.

[45] Acetonitrile is a significant outlier from the general trend, as has been noted previously [Williams et al., 2000]. The acetonitrile variability $\left(\mathrm{s}_{\ln X}=0.22\right)$ is consistent with an atmospheric lifetime of only 55 days, much less than the calculated $\mathrm{OH}$ lifetime of 470 days. There are several possible reasons for this inconsistency. A dramatically different source distribution than the other measured species might result in a different $s_{\ln X^{-}} \tau$ dependence. This is possible, as biomass burning is thought to be the predominant source of acetonitrile to the atmosphere, but is likely a minor contributor to other measured species. However, the remoteness of the sampling station from continental emission sources should minimize the effects of source collocation on observed variability. This is borne out by the strongly consistent trend among the other species, which have a variety of different sources. Another possibility is that of a significant sink mechanism in addition to $\mathrm{OH}$ loss. In particular, there is growing evidence that oceanic uptake may play a major role in the global acetonitrile budget [Warneke and de Gouw, 2001; de Laat et al., 2001; de Gouw et al., 2003]. It is not necessary that this loss mechanism be sufficient to result in an average global lifetime for acetonitrile of only 55 days, since if there are strong uptake regions near Trinidad Head or along the backtrajectory, the local lifetime would be lower than the global mean.

[46] $\mathrm{CO}$ is another outlier from the general trend (not shown), with substantially lower variability than expected based on its $\mathrm{OH}$ lifetime. This is likely due to the widespread, diffuse source of $\mathrm{CO}$ in the atmosphere from methane oxidation, dampening its variability relative to the VOCs. Acetone and MEK are also produced photochemically in addition to having primary sources; however, they fit the general $s_{\ln X^{-}} \tau$ trend, while $\mathrm{CO}$ does not. This 
may indicate that the budgets of these compounds were dominated by direct emissions, or more likely that their photochemical precursors are much more reactive than methane, and consequently not as well mixed in the atmosphere.

[47] Observed variability can be affected both by changes in ambient concentrations and by the precision of the measurement. For most of the compounds employed in this analysis, the observed variability was more than an order of magnitude greater than the estimated precision of measurement. For MEK, methanol, ethanol, isopropanol and chloroform, measured variability was 5-8 times the precision, and any biases to the variability statistics due to measurement precision are unlikely to be significant. For $\mathrm{C}_{2} \mathrm{Cl}_{4}$, methyl chloroform, CFC 11 and CFC 113, however, observed variability was only $1.3-2.2$ times the estimated precision of measurement. The fact that these compounds fit the general $s_{\operatorname{lnX}}-\tau$ trend may thus be somewhat fortuitous. However, excluding these compounds from the analysis did not significantly alter the regression statistics.

[48] The consistent $s_{\ln X}-\tau$ trend among species with varying source types (combustion, evaporative, photochemical, biogenic, marine) is in contrast to modeling results which predict different $s_{\ln X}-\tau$ trends for different source categories [Johnston et al., 2002]. It appears that sampling location plays a central role in determining the coherence of $\mathrm{s}_{\ln X^{-}} \tau$ trends for different types of compounds. We note, however, that the falloff in variability for compounds with $\tau<1$ day, and the higher degree of scatter in the $s_{\ln X^{-}} \tau$ plot at shorter lifetime is consistent with source variability having a more significant impact on $s_{\ln X}$ for these compounds.

\subsubsection{Estimation of $\mathbf{O H}$}

[49] The variability-lifetime curve defined by the VOCs, in conjunction with on-site measurements of radon-222, provides a means of calculating the average $\mathrm{OH}$ during the study period. Ehhalt et al. [1998] also recognized this possibility but were unable to carry it out as they did not have radon data. Radon undergoes radioactive decay with an e-folding time of 5.52 days (half life $=3.82$ days). Subject to the assumption that radon has a similar sourcesink distribution as the VOCs and will therefore fall along the same $s_{\ln X^{-}} \tau$ curve, the variability exhibited by radon gas should then correspond to an atmospheric lifetime of 5.52 days.

[50] Figure 8 shows the radon lifetime calculated from the VOC lifetime-variability curve as a function of the $\mathrm{OH}$ concentration used to derive the $s_{\ln X^{-}} \tau$ fit. A radon lifetime of 5.52 days is indicative of an average $\mathrm{OH}$ concentration of $6.1 \times 10^{5}$ molec $/ \mathrm{cm}^{3}\left( \pm 1\right.$ SE: $4.0 \times 10^{5}-9.2 \times$ $\left.10^{5} \mathrm{molec} / \mathrm{cm}^{3}\right)$. We interpret this as the 24 hour average $\mathrm{OH}$ concentration along the trajectory between the emission region and Trinidad Head. This is within $25 \%$ (and $1 \mathrm{SE}$ ) of the modeled $\mathrm{OH}$ zonal mean of $7.8 \times 10^{5} \mathrm{molec} / \mathrm{cm}^{3}$ for April at $44 \mathrm{~N}$ and $1000 \mathrm{hPa}$ [Spivakovsky et al., 2000].

[51] Trinidad Head is located at 41.054 N. Daytime winds at the site were almost exclusively out of the northwest, and back-trajectory analysis shows that many of the sampled air masses passed through higher latitudes (frequently $60 \mathrm{~N}$ or higher) and elevations en route to Trinidad Head. The model $\mathrm{OH}$ estimate for $44 \mathrm{~N}$ and $1000 \mathrm{hPa}$ thus may not be an entirely accurate reflection of the domain actually encoun-

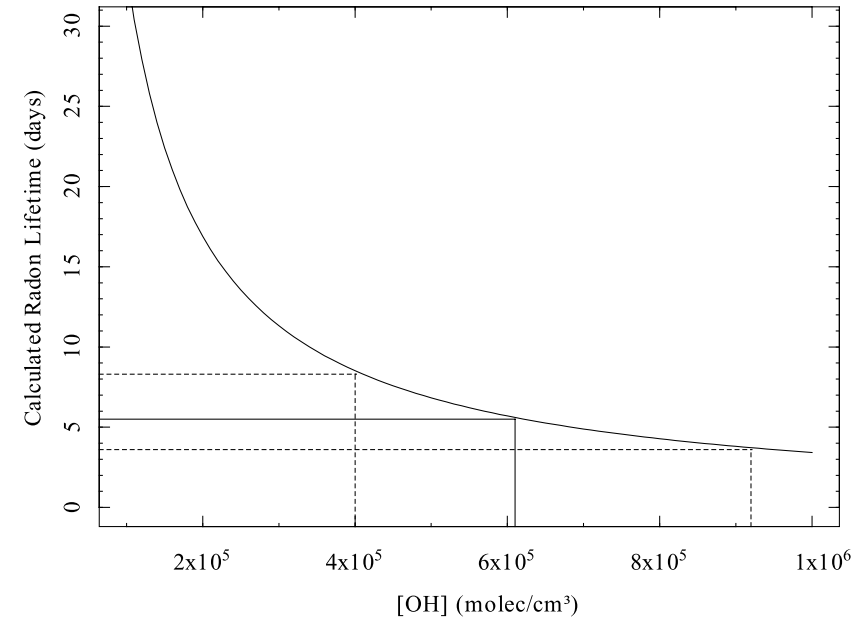

Figure 8. Calculated radon lifetime as a function of the $\mathrm{OH}$ concentration used to derive the VOC lifetimevariability relationship. The actual radon lifetime of 5.52 days is indicative of an average $\mathrm{OH}$ concentration of $6.1 \times$ $10^{5} \mathrm{molec} / \mathrm{cm}^{3}$. The dashed lines indicate \pm 1 standard error.

tered by the air masses sampled during the experiment, and it is reasonable that our variability-lifetime $\mathrm{OH}$ estimate would be somewhat lower.

[52] This calculation of $\mathrm{OH}$ is subject to the assumption that radon falls on the same lifetime-variability trend line as the VOCs. Modeling results [Johnston et al., 2002] suggest that source distribution can significantly affect the variability exhibited by a trace gas of given lifetime. However, at Trinidad Head a strongly consistent variability-lifetime dependence was observed for VOCs with widely varying source types: combustive and evaporative emissions (e.g., aromatic species and light alkanes, respectively); urban/ industrial compounds (e.g., the halocarbons); oceanic emissions (e.g., DMS); photochemically produced compounds (e.g., acetone, MEK); and biogenically emitted species (e.g., methanol, ethanol). This suggests that source differences did not significantly impact the variability-lifetime dependence at Trinidad Head. We conclude that variability in ambient radon concentrations, at least at this location, should be dictated by the same $s_{\ln X}-\tau$ dependence as the VOCs.

\subsubsection{Estimation of Aerosol Residence Times}

[53] The variability-lifetime relationship defined by the VOCs enables calculation of atmospheric residence times for other species measured on-site based on their observed variability. This approach is valid to the extent that the species examined have comparable source-sink distributions as the VOCs, i.e., they are dominantly emitted from common or collocated sources as the VOCs (or are formed in-situ shortly after emission), and undergo a diffuse loss process that is approximately first order. With the exception of acetonitrile and species with $\tau<1$ day, all measured VOCs follow the same variability-lifetime dependence. This encompasses species with a range of different sources (including anthropogenic, biogenic, oceanic, and photochemical production) and with lifetimes varying over 4 orders of magnitude, giving us confidence that the relationship is applicable to other measured species. Here we apply it to estimate lifetimes for various aerosol parameters. 
[54] This discussion focuses on high-time resolution measurements of aerosol chemical composition and number density performed at Trinidad Head during the ITCT $2 \mathrm{~K} 2$ campaign. The analysis is only applicable for measurement systems that are capable of resolving the analyte variability at the lowest occurring concentration levels; otherwise an underestimate of the variability and an overestimate of the atmospheric lifetime will result. Lifetimes calculated in this manner are also directly sensitive to the $\mathrm{OH}$ concentration used in deriving the $\mathrm{s}_{\ln X}-\tau$ fit for the VOCs. A higher (lower) $\mathrm{OH}$ concentration will shift the $\mathrm{s}_{\ln \mathrm{X}^{-}} \tau$ line and result in a shorter (longer) calculated lifetime based on a given variability. Calculated lifetimes are given in Table 5 and discussed below.

\subsubsection{Particle Number Density}

[55] The variability observed at Trinidad Head for particle number concentration $\left(\mathrm{s}_{\ln X}=0.59\right)$ was indicative of a 9.8 day ( \pm 1SE: $6.6-14$ days) residence time. Entrainment of free tropospheric aerosol is thought to be a primary source of aerosol number in the MBL [Raes, 1995; Covert et al., 1996; Bates et al., 1998]. At Trinidad Head, combustion emissions, primarily observed at night during low-wind conditions, also contributed to the observed aerosol number concentrations, as shown in the factor analysis above.

[56] Sinks for particle number include deposition (wet and dry) as well as self-coagulation. Coagulation is a secondorder process and would not necessarily give rise to the same variability-lifetime dependence as obtained for the VOCs. However, aerosol number size distribution in the clean MBL is typically dominated by strong Aitken $\left(0.01 \mu \mathrm{m}<\mathrm{D}_{\mathrm{p}}<\right.$ $0.1 \mu \mathrm{m})$ and accumulation $\left(0.1 \mu \mathrm{m}<\mathrm{D}_{\mathrm{p}}<1 \mu \mathrm{m}\right)$ modes, with nucleation mode particles $\left(\mathrm{D}_{\mathrm{p}}<0.01 \mu \mathrm{m}\right)$ infrequently observed [Raes et al., 2000; Covert et al., 1996]. The coarse sea salt mode is ubiquitously present but contributes little to the number density. Raes et al. [2000] estimated a characteristic time for coagulation and cloud scavenging of 1 day for nucleation mode particles, 7.6 days for Aitken mode particles and 66 days for accumulation mode particles in the clean MBL. In a modeling study, Katoshevski et al. [1999] found coagulation had only a minor effect on MBL aerosol number concentrations. We therefore assume that first-order sinks are of greater importance to the aerosol number concentration budget at Trinidad Head.

[57] Williams et al. [2002] applied a variability-lifetime analysis to size-resolved particle data, and used a combination of numerical simulation and observations to derive aerosol residence time as a function of particle size. They found a strong variability and lifetime dependence on particle size owing to the operation of distinct source and sink mechanisms at different sizes, and estimated an integrated MBL lifetime of 3 days for aerosol with $0.6 \mu \mathrm{m}<\mathrm{D}_{\mathrm{p}}<$ $2.5 \mu \mathrm{m}$. However, for the reasons discussed above, smaller Aitken and accumulation mode particles are likely to be the main component of the total number density at Trinidad Head, which is consistent with a longer residence time.

\subsubsection{Aerosol Nitrate}

[58] A small fraction (7\%) of the PILS-derived nitrate loadings were quantized at $0.008 \mu \mathrm{g} / \mathrm{m}^{3}$, which biased the variability. After removing these values, the AMS and PILS measurements of aerosol nitrate mass exhibited variability resulting in residence time estimates of $5.6( \pm 1 \mathrm{SE}$ : 3.8-8.3) and $3.9( \pm 1 \mathrm{SE}: 2.6-5.7)$ days. These values are consistent
Table 5. Calculated Aerosol Residence Times

\begin{tabular}{lccccc}
\hline & Measurement & Size & & \multicolumn{2}{c}{ Estimated Lifetime } \\
\cline { 6 - 7 } \multicolumn{1}{c}{ Quantity } & Technique & Cutoff & $\mathrm{S}_{\ln X}$ & (Days) & $( \pm 1 \mathrm{SE})$ \\
\hline $\mathrm{NO}_{3}$ & AMS & $2 \mu \mathrm{m}$ & 0.75 & $\mathbf{5 . 6}$ & $(3.8-8.3)$ \\
$\mathrm{NO}_{3}$ & PILS & $1 \mu \mathrm{m}$ & 0.88 & $\mathbf{3 . 9}$ & $(2.6-5.7)$ \\
$\mathrm{SO}_{4}$ & AMS & $2 \mu \mathrm{m}$ & 0.74 & $\mathbf{5 . 7}$ & $(3.9-8.4)$ \\
$\mathrm{SO}_{4}$ & PILS & $1 \mu \mathrm{m}$ & 0.67 & $\mathbf{7 . 1}$ & $(4.8-10)$ \\
$\mathrm{Organics}$ & AMS & $2 \mu \mathrm{m}$ & 0.71 & $\mathbf{6 . 3}$ & $(4.3-9.2)$ \\
$\mathrm{NH}_{4}$ & AMS & $2 \mu \mathrm{m}$ & 0.86 & $\mathbf{4 . 1}$ & $(2.8-6.0)$ \\
$\mathrm{NH}_{4}$ & PILS & $1 \mu \mathrm{m}$ & 1.0 & $\mathbf{2 . 9}$ & $(2.0-4.3)$ \\
MSA & PILS & $1 \mu \mathrm{m}$ & 0.54 & $\mathbf{1 2}$ & $(8.0-17)$ \\
Number Density & CPC & $2.5 \mu \mathrm{m}$ & 0.59 & $\mathbf{9 . 8}$ & $(6.6-14)$ \\
\hline
\end{tabular}

with each other within the estimated uncertainty of the calculation. However, it should be mentioned that there may be another species interfering with the AMS nitrate measurement (for more details see Allan et al. [2004]), which could influence the resulting lifetime estimate.

[59] A primary source of aerosol nitrate in continental air masses is nitric acid dissolution into aqueous aerosol and reaction with ammonia [Adams et al., 1999]. However, previous measurements in the unpolluted MBL have found the vast majority of the nitrate to be in the coarse mode due to reaction with sea salt [Clegg and Brimblecombe, 1985; Raes et al., 2000]. Size resolved nitrate mass measurements at Trinidad Head peaked in the accumulation mode, but also had significant loading in the coarse mode $\left(D_{p}>1 \mu \mathrm{m}\right)$ [Allan et al., 2004]. However, as the AMS particle transmission efficiency decreases for particles larger than $1 \mu \mathrm{m}$, it was not possible to quantify the nitrate partitioning between the sub-micron and super-micron regimes.

[60] Seinfeld and Pandis [1998] estimated a mean tropospheric residence time for particulate $\mathrm{NO}_{3}$ of 3-9 days and our estimate is entirely consistent with that, given the effectiveness of wet and dry deposition in the MBL.

\subsubsection{Aerosol Sulfate}

[61] The AMS and PILS sulfate measurements had similar variability $\left(\mathrm{s}_{\ln X}=0.74\right.$ and 0.67$)$, resulting in consistent sulfate residence time estimates of 5.7 ( $\pm 1 \mathrm{SE}$ : $3.9-8.4)$ and 7.1 ( \pm 1SE: 4.8-10) days, respectively.

[62] Non-sea salt sulfate accounted for more than $95 \%$ of the total sulfate loading on average at Trinidad Head. Sulfur emitted as DMS is thought to constitute a major fraction of non-sea salt sulfate in the unpolluted MBL [Katoshevski et al., 1999; Raes et al., 2000; Mari et al., 1999; Andreae and Crutzen, 1997], and the high observed MSA to non-sea-salt sulfate ratios suggest that this was the case at Trinidad Head. Ambient particulate sulfate in the measured size range was thus presumably dominantly derived from DMS oxidation, and possibly from long-range transport of continental emissions. The AMS time-of-flight data [Allan et al., 2004] shows that the sulfate mass was almost exclusively contained in the accumulation mode.

[63] The calculated residence times are similar to modeled sulfate lifetime estimates of 3.6-7.5 days [Barrie et al., 2001, and references therein] and 3.9-5.7 days [Koch et al., 1999, and references therein], although these reflect global averages and thus should be slightly higher than the MBL residence time.

\subsubsection{Ammonium}

[64] The calculated particle ammonium residence time was 4.1 ( \pm 1 SE: $2.8-6.0)$ days based on the AMS data. The 
lowest concentration PILS ammonium data was quantized at $0.002 \mu \mathrm{g} / \mathrm{m}^{3}$, which biased the variability. When these values (corresponding to $8 \%$ of the observations) were removed, the resulting residence time was $2.9( \pm 1 \mathrm{SE}$ : 2.0-4.3) days, in agreement with the AMS data. Ammonia is known to be emitted in substantial quantities from agricultural practices, natural ecosystems, biomass burning and the surface ocean [Galloway et al., 1995; Dentener and Crutzen, 1994; Liss and Galloway, 1993; Quinn et al., 1988; Jickels et al., 2003], and once emitted, has a short lifetime due to reaction with acidic particles. This loss process will be driven by particle surface area, and thus ammonium was presumably dominantly associated with the acidic sulfate in the accumulation mode. Models have been used to estimate the tropospheric lifetime of particulate ammonium at 4-5 days [Dentener and Crutzen, 1994; Adams et al., 1999], although again these calculations are meant to represent global averages.

\subsubsection{Organic Aerosol}

[65] The calculated residence time for the aerosol organic mass according to the lifetime-variability relationship was $6.3( \pm 1 \mathrm{SE}: 4.3-9.2)$ days, in good agreement with the calculated aerosol sulfate and nitrate residence time. Organic aerosol can be emitted directly in particulate form or produced photochemically in the atmosphere via gas-to-particle conversion. The lifetime of particulate organic matter will depend not only on the size distribution, but also on the solubility of the organic matter and whether or not it is internally mixed with more soluble species such as sulfate [Barth and Church, 1999; Pósfai et al., 1999; Koch, 2001]. At Trinidad Head, the strongest organic mass loading was observed in the accumulation mode [Allan et al., 2004]. In a modeling study, Koch [2001] estimated the tropospheric lifetime of aerosol organic carbon at 3.9 days, slightly shorter than the value calculated for Trinidad Head.

\subsubsection{MSA}

[66] Methane sulfonic acid (MSA) is derived in the atmosphere from oxidation of DMS. The atmospheric residence time estimated for MSA (12 days; $\pm 1 \mathrm{SE}$ : 8.017 days) was longer than that estimated for the other aerosol components (3-7 days for aerosol mass-based parameters, 9.8 days for aerosol number). MSA is present in the gaseous as well as the particulate form [e.g., Berresheim et al., 2002], and it is possible that evaporation-condensation processes are contributing to a longer apparent lifetime. Published estimates of MSA lifetime range from 6-8 days [Koch et al., 1999, and references therein].

\subsubsection{Discussion of Aerosol Residence}

\section{Time Calculation}

[67] The validity of this calculation requires that atmospheric lifetime is the primary determinant of the magnitude of the concentration variability for a given species, and that the loss processes for that species are first order. These requirements are discussed below.

[68] The consistent $S_{\ln X}-\tau$ dependence for VOCs with several different source types indicates that lifetime and not source configuration is the dominant factor determining the magnitude of atmospheric variability at Trinidad Head. However, modeling results suggest that different source distributions can result in different variability being exhibited by a trace species of given lifetime [Johnston et al., 2002], and it is possible that a large nearby source of aerosol such as the ocean may affect the lifetime estimates for certain species. For this reason we have excluded a calculation of sea salt lifetime. Oceanic emissions also influence concentrations of MSA and aerosol sulfate via emission of dimethyl sulfide which is subsequently oxidized. However, DMS concentrations were found to fit the general variability-lifetime relationship. Similarly, airborne VOC measurements over Suriname found that species emitted by the underlying forest (methanol, acetone) nonetheless fit the overall lifetimevariability dependence [Williams et al., 2000]. We have therefore included lifetime estimates for aerosol sulfate and MSA, under the assumption that the same variabilitylifetime dependence observed for the VOCs will nonetheless apply, as it does for DMS. The caveat remains, however, that if this is not the case, the estimated lifetimes for these species may be biased by the presence of nearby oceanic emissions.

[69] With the exception of the particle number data, discussed in detail above, all the aerosol parameters included in this analysis were mass-based. Coagulation can be important in determining the lifetime of a particular size range of aerosol or of total aerosol number concentration, and as it is a second order process, would likely give rise to different $s_{\ln X}-\tau$ dependence than observed for the VOCs. However, coagulation does not represent a sink of aerosol mass, except to the extent that such processes cause particles to grow out of the measured size range. In this experiment the aerosol sampling cutoffs were approximately 1,2 , or $2.5 \mu \mathrm{m}$ depending on the instrument. Raes et al. [2000] estimated the characteristic time for coagulation of accumulation mode particles with clouds and with other accumulation and Aitken mode particles at 66 days in the clean marine boundary layer. Similarly, the characteristic time for volume production by condensational growth was estimated at 52 days for accumulation mode aerosol. Therefore we assume that growth out of the aerosol sampling regime due to coagulation and condensation would be minor loss mechanisms for the particle mass measurements obtained during this study. Wet and dry deposition, which can be approximated as first order loss processes, were likely the dominant sinks.

[70] The size-resolved AMS data offers the opportunity to examine aerosol variability as a function of size as well as chemical composition. However, non-first order processes such as coagulation, which do not affect the integrated mass loading, can be important sinks for individual size fractions within the submicron aerosol, and thus these size fractions are likely to have a different variability dependence on lifetime than the VOCs. For this reason, we restrict this analysis to the integrated chemical composition data, which as discussed above are more likely to follow the same $s_{\ln X^{-}} \tau$ dependence as the gas phase compounds.

\section{Conclusions}

[71] High time resolution speciated VOC measurements were obtained at Trinidad Head during ITCT 2K2, encompassing a wide range of compounds with varying sources, functionalities, and lifetimes. Factor analysis of 
the VOC data set permitted characterization of the sources and processes that were important in determining atmospheric composition at the site. The framework defined by the VOC factor analysis also provided a valuable tool for defining the major processes driving the temporal behavior of other gas and aerosol species measured onsite.

[72] MTBE proved to be a useful marker of recent North American emissions. Filtering the data according to MTBE enabled quantification of the inflow chemical composition at Trinidad Head. This is of interest since the composition of air entering North America from the Pacific helps determine the boundary conditions for North American air quality. OVOCs were the dominant compound class contributing to the total measured gas-phase VOC burden and the VOC OH reactivity at Trinidad Head. Their relative importance was greater under conditions when local source contributions were minimal. This agrees with other recent findings [Singh et al., 2001], and indicates that oxygenated VOCs are an extremely important contributor to MBL composition and photochemistry. However, $\mathrm{CO}$ was the largest contributor to the total $\mathrm{OH}$ loss rate at all times.

[73] VOC variability was found to have a strong dependence on lifetime, $s_{\ln X}=(1.55 \pm 0.17) \tau^{(-0.44 \pm 0.03)}$, with $r^{2}=$ 0.98 . This relationship held for nearly all measured species with lifetimes ranging from $10^{0}$ to $10^{4}$ days. Acetonitrile was the only significant exception, and we hypothesize that its lack of fit to the variability-lifetime relationship arose from strong oceanic uptake which resulted in a shorter local lifetime than expected based solely on reaction with $\mathrm{OH}$.

[74] We have estimated an average $\mathrm{OH}$ concentration of $6.1 \times 10^{5} \mathrm{molec} / \mathrm{cm}^{3}$ for the Trinidad Head experiment. This represents the 24 hour mean $\mathrm{OH}$ concentration encountered by air masses en route to the sampling site, and is similar to model results for this region and time of year [Spivakovsky et al., 2000].

[75] The VOC variability-lifetime analysis also enabled estimation of submicron aerosol residence times as a function of chemical composition. As far as we are aware this represents the first such application of the VOC variabilitylifetime relationship. The AMS and PILS measurements of aerosol chemical composition yielded residence time estimates which were in good agreement. The calculated lifetimes were between 3-7 days for nitrate, sulfate, aerosol organics and and ammonium. The lifetime calculated for MSA (12 days) was slightly longer than other components. The aerosol number density lifetime was calculated at 9.8 days.

[76] The two different analyses of temporal variability (factor analysis and a variability-lifetime analysis) carried out in this paper provided different kinds of information regarding atmospheric composition and processes. Future work incorporating both aerosol chemical composition and speciated VOC measurements should help further our understanding of particle formation, transport and loss mechanisms in different types of environments.

[77] Acknowledgments. This work was supported by the NOAA Office of Global Programs (grant NA16GP2314). The authors thank Eric Williams for providing the $\mathrm{NO} / \mathrm{NO}_{\mathrm{y}}$ data and David Parrish for his help and comments. DBM thanks the DOE Global Change Education program for a GREF fellowship, and Dan Riemer for his generous help and many useful discussions. We thank two anonymous reviewers who provided useful and thoughtful comments.

\section{References}

Adams, P. J., J. H. Seinfeld, and D. M. Koch (1999), Global concentrations of tropospheric sulfate, nitrate, and ammonium aerosol simulated in a general circulation model, J. Geophys. Res., 104(D11), 13,79113,823 .

Allan, J. D., J. L. Jimenez, P. I. Williams, M. R. Alfarra, K. N. Bower, J. T. Jayne, H. Coe, and D. R. Worsnop (2003), Quantitative sampling using an Aerodyne aerosol mass spectrometer, 1, Techniques of data interpretation and error analysis, J. Geophys. Res., 108(D3), 4090, doi:10.1029/ 2002JD002358.

Allan, J. D., et al. (2004), Submicron aerosol composition at Trinidad Head, California, during ITCT 2K2: Its relationship with gas-phase volatile organic carbon and assessment of instrument performance, J. Geophys. Res., 109, D23S24, doi:10.1029/2003JD004208, in press.

Andreae, M. O., and P. J. Crutzen (1997), Atmospheric aerosols: Biogeochemical sources and role in atmospheric chemistry, Science, 276(5315), $1052-1058$

Atkinson, R. (1994), Gas phase tropospheric chemistry of organic compounds, J. Phys. Chem. Ref. Data Monogr., 2.

Barrie, L. A., et al. (2001), A comparison of large-scale atmospheric sulphate aerosol models (COSAM): Overview and highlights, Tellus, Ser. B, 53(5), 615-645.

Barth, M. C., and A. T. Church (1999), Regional and global distributions and lifetimes of sulfate aerosols from Mexico city and southeast China, J. Geophys. Res., 104(D23), 30,231-30,239.

Bates, T. S., J. A. Calhoun, and P. K. Quinn (1992), Variations in the methanesulfonate to sulfate molar ratio in submicrometer marine aerosol particles over the South-Pacific Ocean, J. Geophys. Res., 97(D9), 98599865.

Bates, T. S., V. N. Kapustin, P. K. Quinn, D. S. Covert, D. J. Coffman, C. Mari, P. A. Durkee, W. J. De Bruyn, and E. S. Saltzman (1998), Processes controlling the distribution of aerosol particles in the lower marine boundary layer during the First Aerosol Characterization Experiment (ACE 1), J. Geophys. Res., 103(D13), 16,369-16,383.

Berresheim, H., T. Elste, H. G. Tremmel, A. G. Allen, H.-C. Hansson, K. Rosman, M. Dal Maso, J. M. Mäkelä, M. Kulmala, and C. D. O'Dowd (2002), Gas-aerosol relationships of $\mathrm{H}_{2} \mathrm{SO}_{4}, \mathrm{MSA}$, and $\mathrm{OH}$ : Observations in the coastal marine boundary layer at Mace Head, Ireland, J. Geophys. Res., 107(D19), 8100, doi:10.1029/2000JD000229.

Clegg, S. L., and P. Brimblecombe (1985), Potential degassing of hydrogen chloride from acidified sodium chloride droplets, Atmos. Environ., 19(3), $465-470$.

Colman, J. J., D. R. Blake, and F. S. Rowland (1998), Atmospheric residence time of $\mathrm{CH}_{3} \mathrm{Br}$ estimated from the Junge spatial variability relation, Science, 281(5375), 392-396.

Covert, D. S., V. N. Kapustin, T. S. Bates, and P. K. Quinn (1996), Physical properties of marine boundary layer aerosol particles of the mid-Pacific in relation to sources and meteorological transport, J. Geophys. Res., 101(D3), 6919-6930.

de Gouw, J. A., C. Warneke, D. D. Parrish, J. S. Holloway, M. Trainer, and F. C. Fehsenfeld (2003), Emission sources and ocean uptake of acetonitrile $\left(\mathrm{CH}_{3} \mathrm{CN}\right)$ in the atmosphere, J. Geophys. Res., 108(D11), 4329, doi:10.1029/2002JD002897.

de Laat, A. T. J., J. A. de Gouw, J. Lelieveld, and A. Hansel (2001), Model analysis of trace gas measurements and pollution impact during INDOEX, J. Geophys. Res., 106(D22), 28,469-28,480.

Dentener, F. J., and P. J. Crutzen (1994), A 3-dimensional model of the global ammonia cycle, J. Atmos. Chem., 19(4), 331-369.

Ehhalt, D. H., F. Rohrer, A. Wahner, M. J. Prather, and D. R. Blake (1998), On the use of hydrocarbons for the determination of tropospheric $\mathrm{OH}$ concentrations, J. Geophys. Res., 103(D15), 18,981-18,997.

Fried, A., Y. N. Lee, G. Frost, B. Wert, B. Henry, J. R. Drummond, G. Hubler, and T. Jobson (2002), Airborne $\mathrm{CH}_{2} \mathrm{O}$ measurements over the North Atlantic during the 1997 NARE campaign: Instrument comparisons and distributions, J. Geophys. Res., 107(D4), 4039, doi:10.1029/ 2000JD000260.

Fried, A., et al. (2003), Tunable diode laser measurements of formaldehyde during the TOPSE 2000 study: Distributions, trends, and model comparisons, J. Geophys. Res., 108(D4), 8365, doi:10.1029/ 2002JD002208.

Fuentes, J. D., et al. (2000), Biogenic hydrocarbons in the atmospheric boundary layer: A review, Bull. Am. Meteorol. Soc., 81(7), 15371575 .

Galloway, J. N., W. H. Schlesinger, H. Levy, A. Michaels, and J. L. Schnoor (1995), Nitrogen fixation: Anthropogenic enhancement-environmental response, Global Biogeochem. Cycles, 9(2), 235-252.

Gibbs, A. G., and W. G. N. Slinn (1973), Fluctuations in trace gas concentrations in the troposphere, J. Geophys. Res., 78(3), 574-576.

Goldan, P. D., W. C. Kuster, F. C. Fehsenfeld, and S. A. Montzka (1995), Hydrocarbon measurements in the southeastern United States: The Rural 
Oxidants in the Southern Environment (ROSE) program 1990, J. Geophys. Res., 100(D12), 25,945-25,963.

Goldstein, A. H., and G. W. Schade (2000), Quantifying biogenic and anthropogenic contributions to acetone mixing ratios in a rural environment, Atmos. Environ., 34(29-30), 4997-5006.

Goldstein, A. H., S. C. Wofsy, and C. M. Spivakovsky (1995), Seasona variations of nonmethane hydrocarbons in rural New England: Constraints on $\mathrm{OH}$ concentrations in northern midlatitudes, J. Geophys. Res., 100(D10), 21,023-21,033.

Goldstein, A. H., S. M. Fan, M. L. Goulden, J. W. Munger, and S. C. Wofsy (1996), Emissions of ethene, propene, and 1-butene by a midlatitude forest, J. Geophys. Res., 101(D4), 9149-9157.

Goldstein, A. H., D. B. Millet, M. McKay, L. Jaeglé, L. Horowitz, O. Cooper R. Hudman, D. J. Jacob, S. Oltmans, and A. Clarke (2004), Impact of Asian emissions on observations at Trinidad Head, California, during ITCT 2K2, J. Geophys. Res., 109, D23S17, doi:10.1029/2003JD004406, in press.

Gschwend, P. M., O. C. Zafiriou, R. F. C. Mantoura, R. P. Schwarzenbach, and R. B. Gagosian (1982), Volatile organic compounds at a coastal site. 1. Seasonal variations, Environ. Sci. Technol., 16(1), 31-38.

Hamrud, M. (1983), Residence time and spatial variability for gases in the atmosphere, Tellus, Ser. B, 35(5), 295-303.

Heikes, B. G., et al. (2002), Atmospheric methanol budget and ocean implication, Global Biogeochem. Cycles, 16(4), 1133, doi:10.1029/ 2002GB001895.

Jacob, D. J., B. D. Field, E. M. Jin, I. Bey, Q. B. Li, J. A. Logan, R. M. Yantosca, and H. B. Singh (2002), Atmospheric budget of acetone, J. Geophys. Res., 107(D10), 4100, doi:10.1029/2001JD000694.

Jaenicke, R. (1982), Physical aspects of the atmospheric aerosol, in Chemistry of the Unpolluted and Polluted Troposphere, edited by H. W. Georgii and W. Jaeschke, pp. 341-373, Kluwer, Norwell, Mass.

Jayne, J. T., D. C. Leard, X. F. Zhang, P. Davidovits, K. A. Smith, C. E. Kolb, and D. R. Worsnop (2000), Development of an aerosol mass spectrometer for size and composition analysis of submicron particles, Aero sol Sci. Technol., 33(1-2), 49-70.

Jickells, T. D., S. D. Kelly, A. R. Baker, K. Biswas, P. F. Dennis, L. J Spokes, M. Witt, and S. G. Yeatman (2003), Isotopic evidence for a marine ammonia source, Geophys. Res. Lett, 30(7), 1374, doi:10.1029/ 2002GL016728.

Jimenez, J. L., et al. (2003), Ambient aerosol sampling using the Aerodyne Aerosol Mass Spectrometer, J. Geophys. Res., 108(D7), 8425 , doi:10.1029/2001JD001213.

Jobson, B. T., Z. Wu, H. Niki, and L. A. Barrie (1994), Seasonal trends of isoprene, $\mathrm{C}_{2}-\mathrm{C}_{5}$ alkanes, and acetylene at a remote boreal site in Canada, J. Geophys. Res., 99(D1), 1589-1599.

Jobson, B. T., D. D. Parrish, P. Goldan, W. Kuster, F. C. Fehsenfeld, D. R Blake, N. J. Blake, and H. Niki (1998), Spatial and temporal variability of nonmethane hydrocarbon mixing ratios and their relation to photochemical lifetime, J. Geophys. Res., 103(D11), 13,557-13,567.

Jobson, B. T. S. A. McKeen, D. D. Parrish, F. C. Fehsenfeld, D. R Blake, A. H. Goldstein, S. M. Schauffler, and J. C. Elkins (1999) Trace gas mixing ratio variability versus lifetime in the troposphere and stratosphere: Observations, J. Geophys. Res., 104(D13), 16,09116,113 .

Johnston, N. A. C., J. J. Colman, D. R. Blake, M. J. Prather, and F. S Rowland (2002), On the variability of tropospheric gases: Sampling, loss patterns, and lifetime, J. Geophys. Res., 107(D11), 4111, doi:10.1029/ 2001JD000669

Junge, C. E. (1963), Air Chemistry and Radioactivity, Academic, San Diego, Calif.

Junge, C. E. (1974), Residence time and variability of tropospheric trace gases, Tellus, 26(4), 477-488.

Karl, T., P. J. Crutzen, M. Mandl, M. Staudinger, A. Guenther, A. Jordan, R. Fall, and W. Lindinger (2001), Variability-lifetime relationship of VOCs observed at the Sonnblick Observatory 1999: Estimation of HO-densities, Atmos. Environ., 35(31), 5287-5300.

Katoshevski, D., A. Nenes, and J. H. Seinfeld (1999), A study of processes that govern the maintenance of aerosols in the marine boundary layer, J. Aerosol. Sci., 30(4), 503-532.

Koch, D. (2001), Transport and direct radiative forcing of carbonaceous and sulfate aerosols in the GISS GCM, J. Geophys. Res., 106(D17), 20,31120,332 .

Koch, D., D. Jacob, I. Tegen, D. Rind, and M. Chin (1999), Tropospheric sulfur simulation and sulfate direct radiative forcing in the Goddard Institute for Space Studies general circulation model, J. Geophys. Res. 104(D19), 23,799-23,822.

Koga, S., and H. Tanaka (1999), Modeling the methanesulfonate to nonsea-salt sulfate molar ratio and dimethylsulfide oxidation in the atmosphere, J. Geophys. Res., 104(D11), 13,735-13,747.
Lamanna, M. S., and A. H. Goldstein (1999), In situ measurements of $\mathrm{C}_{2}-$ $\mathrm{C}_{10}$ volatile organic compounds above a Sierra Nevada ponderosa pine plantation, J. Geophys. Res., 104(D17), 21,247-21,262.

Liss, P. S., and J. N. Galloway (1993), Air-sea exchange of sulphur and nitrogen and their interaction in the marine atmosphere, in Interactions of $C, N, P$, and S Biogeochemical Cycles and Global Change, edited by R. Wollast, F. T. Mackenzie, and L. Chou, pp. 259-281, Springer-Verlag, New York

Mari, C., K. Suhre, R. Rosset, T. S. Bates, B. J. Huebert, A. R. Bandy, D. C. Thornton, and S. Businger (1999), One-dimensional modeling of sulfur species during the First Aerosol Characterization Experiment (ACE 1) Lagrangian B, J. Geophys. Res., 104(D17), 21,733-21,749.

McKeen, S. A., and S. C. Liu (1993), Hydrocarbon ratios and photochemical history of air masses, Geophys. Res. Lett., 20(21), 23632366.

Millet, D. B., N. M. Donahue, S. N. Pandis, A. Polidori, C. O. Stanier, B. J. Turpin, and A. H. Goldstein (2004), Atmospheric VOC measurements during the Pittsburgh Air Quality Study: Results, interpretation, and quantification of primary and secondary contributions, J. Geophys. Res., 109, doi:10.1029/2004JD004601, in press

Nuccio, J., P. J. Seaton, and R. J. Kieber (1995), Biological production of formaldehyde in the marine environment, Limnol. Oceanogr., 40(3), $521-527$.

Orsini, D. A., Y. L. Ma, A. Sullivan, B. Sierau, K. Baumann, and R. J. Weber (2003), Refinements to the particle-into-liquid sampler (PILS) for ground and airborne measurements of water soluble aerosol composition, Atmos. Environ., 37(9-10), 1243-1259.

Palmer, P. I., D. J. Jacob, L. J. Mickley, D. R. Blake, G. W. Sachse, H. E. Fuelberg, and C. M. Kiley (2003), Eastern Asian emissions of anthropogenic halocarbons deduced from aircraft concentration data, J Geophys. Res., 108(D24), 4753, doi:10.1029/2003JD003591.

Parrish, D. D., C. J. Hahn, E. J. Williams, R. B. Norton, F. C. Fehsenfeld, H. B. Singh, J. D. Shetter, B. W. Gandrud, and B. A. Ridley (1992), Indications of photochemical histories of Pacific air masses from measurements of atmospheric trace species at Point Arena, California, J. Geophys. Res., 97(D14), 15,883-15,901.

Plass-Dülmer, C., R. Koppmann, M. Ratte, and J. Rudolph (1995), Light nonmethane hydrocarbons in seawater, Global Biogeochem. Cycles, 9(1), $79-100$

Pósfai, M., J. R. Anderson, P. R. Buseck, and H. Sievering (1999), Soot and sulfate aerosol particles in the remote marine troposphere, J. Geophys. Res., 104(D17), 21,685-21,693.

Quinn, P. K., R. J. Charlson, and T. S. Bates (1988), Simultaneous observations of ammonia in the atmosphere and ocean, Nature, 335(6188), 336338 .

Raes, F. (1995), Entrainment of free tropospheric aerosols as a regulating mechanism for cloud condensation nuclei in the remote marine boundary layer, J. Geophys. Res., 100(D2), 2893-2903.

Raes, F., R. Van Dingenen, E. Vignati, J. Wilson, J. P. Putaud, J. H. Seinfeld, and P. Adams (2000), Formation and cycling of aerosols in the global troposphere, Atmos. Environ., 34(25), 4215-4240.

Sander, S. P., et al. (2002), Chemical Kinetics and Photochemical Data for Use in Atmospheric Studies: Evaluation Number 14, JPL Publication 02-25, Jet Propulsion Lab., Pasadena, Calif.

Savoie, D. L., R. Arimoto, W. C. Keene, J. M. Prospero, R. A. Duce, and J. N. Galloway (2002), Marine biogenic and anthropogenic contributions to non-sea-salt sulfate in the marine boundary layer over the North Atlantic Ocean, J. Geophys. Res., 107(D18), 4356, doi:10.1029/2001JD000970.

Seinfeld, J. H., and S. N. Pandis (1998), Atmospheric Chemistry and Physics: From Air Pollution to Climate Change, John Wiley, Hoboken, N. J.

Singh, H., Y. Chen, A. Staudt, D. Jacob, D. Blake, B. Heikes, and J. Snow (2001), Evidence from the Pacific troposphere for large global sources of oxygenated organic compounds, Nature, 410(6832), 1078-1081.

Slinn, W. G. N. (1988), A simple model for Junge's relationship between concentration fluctuations and residence times for tropospheric trace gases, Tellus, Ser. B, 40(3), 229-232.

Spivakovsky, C. M., R. Yevich, J. A. Logan, S. C. Wofsy, M. B. McElroy, and M. J. Prather (1990), Tropospheric $\mathrm{OH}$ in a 3-dimensional chemical tracer model: An assessment based on observations of $\mathrm{CH}_{3} \mathrm{CCl}_{3}, \mathrm{~J}$. Geophys. Res., 95(D11), 18,441-18,471.

Spivakovsky, C. M., et al. (2000), Three-dimensional climatological distribution of tropospheric OH: Update and evaluation, J. Geophys. Res., 105(D7), 8931-8980.

Swanson, A. L., N. J. Blake, E. Atlas, F. Flocke, D. R. Blake, and F. S. Rowland (2003), Seasonal variations of $\mathrm{C}_{2}-\mathrm{C}_{4}$ nonmethane hydrocarbons and $\mathrm{C}_{1}-\mathrm{C}_{4}$ alkyl nitrates at the Summit research station in Greenland, J. Geophys. Res., 108(D2), 4065, doi:10.1029/2001JD001445.

Warneke, C., and J. A. de Gouw (2001), Organic trace gas composition of the marine boundary layer over the northwest Indian Ocean in April 2000, Atmos. Environ., 35(34), 5923-5933. 
Weber, R. J., D. Orsini, Y. Daun, Y. N. Lee, P. J. Klotz, and F. Brechtel (2001), A particle-into-liquid collector for rapid measurement of aerosol bulk chemical composition, Aerosol Sci. Technol., 35(3), $718-$ 727.

Whittlestone, S., and W. Zahorowski (1998), Baseline radon detectors for shipboard use: Development and deployment in the First Aeroso Characterization Experiment (ACE 1), J. Geophys. Res., 103(D13), $16,743-16,751$

Williams, J., et al. (2000), Variability-lifetime relationship for organic trace gases: A novel aid to compound identification and estimation of $\mathrm{HO}$ concentrations, J. Geophys. Res., 105(D16), 20,473-20,486.

Williams, J., V. Gros, B. Bonsang, and V. Kazan (2001), HO cycle in 1997 and 1998 over the southern Indian Ocean derived from CO, radon, and hydrocarbon measurements made at Amsterdam Island, J. Geophys. Res., 106(D12), 12,719-12,725.

Williams, J., M. de Reus, R. Krejci, H. Fischer, and J. Strom (2002), Application of the variability-size relationship to atmospheric aerosol studies: Estimating aerosol lifetimes and ages, Atmos. Chem. Phys., 2, $133-145$.

Zhang, X. F., K. A. Smith, D. R. Worsnop, J. Jimenez, J. T. Jayne, and C. E. Kolb (2002), A numerical characterization of particle beam collimation by an aerodynamic lens-nozzle system: Part I. An individual lens or nozzle, Aerosol Sci. Technol., 36(5), 617-631.

Zhou, X. L., and K. Mopper (1997), Photochemical production of lowmolecular-weight carbonyl compounds in seawater and surface microlayer and their air-sea exchange, Mar. Chem., 56(3-4), 201-213.

J. D. Allan, K. N. Bower, and H. Coe, Department of Physics, University of Manchester Institute of Science and Technology, PO Box 88, Manchester M60 1QD, UK

T. S. Bates and P. K. Quinn, Pacific Marine Environmental Laboratory, NOAA, 7600 Sand Point Way NE, Seattle, WA 98115, USA.

H. Boudries and D. R. Worsnop, Aerodyne Research Incorporated, 45 Manning Road, Billerica, MA 01821, USA.

A. H. Goldstein, D. B. Millet, and M. McKay, ESPM - Ecosystem Sciences, UC Berkeley, 151 Hilgard Hall, Berkeley, CA 94720, USA. (dylan@atmos.berkeley.edu; ahg@nature.berkeley.edu)

Y. Ma, A. Sullivan, and R. J. Weber, School of Earth and Atmospheric Sciences, Georgia Institute of Technology, 221 Bobby Dodd Way, Atlanta, GA 30332, USA. 